Est Ag 51 (2016) 591-630

\title{
Viaje apostólico a Cuba y a Estados Unidos de América
}

\author{
Prof. Dr. EnRiQue Somavilla Rodríguez, OSA \\ Director del Centro Teológico San Agustín CTSA
}

RESUMEN: El décimo viaje apostólico del papa Francisco tenía como itinerario la visita a la República Cubana, los Estados Unidos de América y la visita a la sede de la Organización de las Naciones Unidas, con motivo de su participación en el VIII Encuentro Mundial de las Familias, en Filadelfia, del 18 al 28 de septiembre de 2015 . Un viaje muy esperado tras el giro en la política norteamericana respecto a Cuba y el discutido embargo, consecuencia de la crisis de los misiles y último rescoldo de la guerra fría en octubre de 1962. Éxito sin precedentes de la estrategia de la Santa Sede. Un itinerario difícil y complicado ante la apuesta de aquella por ayudar a normalizar las relaciones diplomáticas entre ambos países. Además de la enérgica oposición de grupos conservadores a dicho viaje papal. El futuro deparará los frutos obtenidos que pueden otearse en el horizonte.

Palabras Clave: Santa Sede, Cuba, EE. UU., relaciones diplomáticas, viaje apostólico

Summary: The tenth apostolic trip of Pope Francis had as schedule a visit to the Cuban republic, the United States and the visit to the Headquarters of the United Nations, during its participation in the VIII World Meeting of Families, in Philadelphia, from 18th to 28th September 2015. It was a long awaited trip after the turn in US policy toward Cuba and discussed embargo, consequence of the missile crisis and last embers of the cold war in October 1962. It is unprecedented success of the strategy of the Holy See: A difficult and complicated itinerary after the decision of USA to normalize diplomatic relations between both countries. The papal trip faced up a strong opposition from conservative groups. The future will bring the fruits obtained that can scan on the horizon.

KEYwords: Holy See, Cuba, USA, Diplomatic relations, apostolic trip. 


\section{Introducción}

El décimo viaje apostólico del Santo Padre a Cuba, a los Estados Unidos de América y a la sede de la Organización de las Naciones Unidas, del 19 al 28 de septiembre de 2015, se perfilaba como uno de los más difíciles de los realizados hasta ese momento, por su complejidad, repercusión y trascendencia, no sólo apostólico y religioso sino por su sentido social o político. El papa salía del aeropuerto de Roma-Fiumicino a las 10,15 de la mañana, en Alitalia, como exige el protocolo. Llegaba al aeropuerto internacional José Martí de La Habana a las 16,00.

Los primeros vínculos entre la Sede Apostólica y Cuba comenzaron en el mismo año de 1898 con la llegada a la isla de mons. Plácide-Luis Chapelle como primer Delegado apostólico. Pero las relaciones diplomáticas se establecieron de manera oficial en 1935 durante el pontificado de Su Santidad el papa Pío XI. En aquellos momentos, Cuba fue una de las primeras Repúblicas de América Latina en aunar puentes con la Santa Sede. Ya en 1927 se había producido una propuesta de Ley acerca de las relaciones diplomáticas que sería debatida en la Cámara de Representantes de Cuba, a petición del Excmo. Sr. Santiago Claret y de otros miembros del Parlamento cubano.

Mientras tanto, la representación diplomática ante la Santa Sede estuvo a cargo del embajador cubano en París hasta el año 1936. En este año fue acreditado ante Su Santidad Pío XI, el embajador designado por La Habana. Será a partir del 7 de junio de 1935 el Presidente Provisional de Cuba, Coronel Carlos Mendieta, a propuesta del Excmo. Sr. José A. Barnet, Ministro de Relaciones Exteriores y futuro Presidente Provisional, firmó el Decreto Ley $\mathrm{N}^{\circ} 208$ por el que acordaba la creación de la Legación de la República de Cuba ante la Santa Sede acreditando un Enviado Extraordinario y Ministro Plenipotenciario e igualmente un secretario de Legación de Primera Clase. La comunicación oficial fue dirigida por el mismo Ministerio a la Santa Sede, el cardenal Eugenio Pacelli, secretario de Estado y futuro Pío XII, donde se congratulaba y expresaba la complacencia del papa Pío XI por el creciente deseo de los Estados de estrechar sus relaciones con la Santa Sede; y secundaba tan noble decisión disponiendo constituir una Nunciatura apostólica ante la República de Cuba. El 26 de septiembre de 1935 el cardenal Pacelli enviaba dos Breves Apostólicos, con los cuales, Su Santidad el papa Pío XI creaba ad perpetuam rei memoriam la Nunciatura apostólica mediante el Breve Reipublicae Cubanae Gubernatores ${ }^{1}$, del 11 de septiembre de 1935, y nombraba Nuncio apostólico a Su Excelencia mons. Giorgio Giu-

${ }^{1}$ Cf. Pío XI, "Carta Apostólica Reipublicae Cubanae Gubernatores", en AAS 28 (1936) 64-65. 
seppe Caruana, con fecha 15 del mismo mes; el cual, desde 1925 había sido Delegado apostólico en las Antillas, México y Cuba.

El 6 de diciembre de 1935 mons. Caruana presentó sus Cartas Credenciales al Presidente Provisional de la República, el Coronel Carlos Mendieta. Mientras que el 20 de enero de 1936, mediante el Decreto $\mathrm{N}^{\circ}$ 81 del Presidente de la República, fue reconocido como Decano del Cuerpo Diplomático. Tras la revolución cubana de 1959, la Iglesia se opuso al nuevo régimen comunista, que reaccionó expulsando a un centenar de religiosos y nacionalizando numerosos bienes eclesiásticos. En un principio la ubicación de la Delegación apostólica fue el obispado de san Cristóbal de La Habana. Posteriormente, en 1922, se trasladó a la esquina formada por las calles 20 y 15, Reparto El Carmelo, del Barrio Vedado. El 12 de marzo de 1953 con ocasión del XIV aniversario del pontificado del papa Pío XII, se inauguró la sede definitiva de la Nunciatura apostólica en la calle $12 \mathrm{~N}^{\circ} 514$ de Miramar, Playa, La Habana ${ }^{2}$. Entre los acontecimientos más relevantes se encuentran: del 28 marzo al 5 de abril de 1974, gira una visita a Cuba, mons. Agostino Casaroli, en ese momento, secretario para los Asuntos Públicos de la Iglesia. Más tarde, del 25 al 29 de octubre de 1996, llega a Cuba, mons. Jean-Louis Tauran, en ese tiempo, secretario para las Relaciones con los Estados. Más tarde se produce el encuentro entre Fidel Castro Ruz con el papa Juan Pablo II, en la Ciudad del Vaticano, el 19 de noviembre de 1996. Sería del 21 al 25 de enero de 1998, cuando se realiza la visita histórica del papa san Juan Pablo II a Cuba, alojándose en la sede de la Nunciatura apostólica desde la cual peregrinó a Santa Clara, Camagüey, Santiago de Cuba y La Habana. El Santo Padre animó a los cubanos a ser protagonistas de su historia, destacó los valores patrios e invitó a continuar la síntesis entre Fe y Cultura iniciada por el P. Félix Varela. Dio gracias a Dios por el gran don de la familia, ofreció a los jóvenes un programa de vida personal y social, se acercó a los que sufren en el alma y en el cuerpo, coronó a la imagen de Nuestra Señora de la Caridad del Cobre como Reina de Cuba y exhortó a todos: Abrir las puertas a Cristo. Sería de gran resonancia sus palabras de "Que Cuba se abra al mundo y el mundo se abra a Cuba"3.

\footnotetext{
2 Cf. http://www.nunciaturacuba.net/ Visto 11-010-2015.

3 "Que Cuba se abra con todas sus magníficas posibilidades al mundo y que el mundo se abra a Cuba". Juan Pablo II, Discurso en la ceremonia de llegada a La Habana (Cuba) el 21 de enero de 1998. Cf. http://w2.vatican.va/content/john-paul-ii/es/speeches/1998/january/documents/hf_jp-ii_spe_19980121_lahavana-arrival.html Visto 11-102015; También JuAn PABLo II, "Discurso del Santo Padre a su llegada al aeropuerto de La Habana (21-01-1998)”, en Ecclesia 2879 (07-02-1998) 20-21.
} 
La visita consiguió que se reconociese como fiesta la Navidad. A partir del 1 al 3 de diciembre de 1999, se produce la visita a Cuba de mons. Jean-Louis Tauran, en ese momento, secretario para las Relaciones con los Estados. Más tarde, del 20 al 26 de febrero de 2008, visita Cuba el cardenal Tarcisio Bertone, entonces, secretario de Estado, con ocasión del X aniversario del viaje apostólico de san Juan Pablo II a Cuba. El día 4 de junio de 2008, se realiza la visita del Excmo. Sr. Dr. José Machado Ventura, Vicepresidente de los Consejos de Estado y de Ministros, al cardenal Tarcisio Bertone. Dos años más tarde, del 15 al 20 de junio de 2010, gira visita a Cuba, mons. Dominique Mamberti, entonces secretario para las Relaciones con los Estados, con ocasión de los LXXV años de relaciones diplomáticas entre la Santa Sede y Cuba. El punto de mayor fuerza se realiza del 26 al 28 de marzo de 2012, con la visita del Santo Padre Benedicto XVI. A diferencia de Juan Pablo II, Benedicto XVI inició su visita desde la ciudad de Santiago de Cuba, donde ofició una misa. Al día siguiente emprendió viaje hacia La Habana. La visita consiguió igualmente el reconocimiento de la Semana Santa. Fue un viaje donde se ahondó en las relaciones bilaterales entre ambas partes y sus implicaciones para la Iglesia católica en Cuba. El acercamiento en las relaciones, daría lugar, tres años más tarde, al viaje apostólico del Santo Padre Francisco a Cuba, previa visita realizada por Raúl Castro Ruz al Santo Padre en el Estado de la Ciudad del Vaticano el 10 de mayo de 2015.

El primer paso en las relaciones entre ambos Estados data del 4 de junio de 1784 el papa Pío VI (Giovanni Angelo Braschi) nombró al jesuita John Carroll como prefecto apostólico de los Estados Unidos, pero con un título diferente: Superior de la Misión en trece Estados. La Prefectura fue instituida oficialmente el 26 de noviembre de 1784, la primera circunscripción eclesiástica en EEUU. Las relaciones entre los Estados Unidos de América y la Santa Sede se inician en 1788, cuando el presidente George Washington aseguró al papa Pío VI que tendría plena libertad para nombrar obispos en EE.UU. Un año más tarde, el jesuita John Carroll fue elegido el primer obispo de Baltimore, así como el primer obispo católico en los Estados Unidos.

Estados Unidos, a partir de 1797, mantuvo relaciones consulares con los entonces Estados pontificios, integrados hoy, en su mayor parte, en Italia. Más tarde en 1848, pero posteriormente por diversas causas, entre ellas la hostilidad hacia los católicos, llevaron al Congreso a sancionar una ley que prohibía la concesión de créditos para el mantenimiento de una embajada de Estados Unidos en el Vaticano. Sería, en 1868, cuando 
la embajada cerró sus puertas, dos años antes del final de los Estados pontificios y tanto las relaciones diplomáticas como las relaciones consulares fueron suspendidas igualmente al desaparecer los Estados pontificios. El 15 de marzo 1875 el papa Pío IX creó el primer cardenal estadounidense, el arzobispo de Nueva York, John McCloskey. El 9 de enero 1919, Woodrow Wilson, fue el primer presidente de EE.UU. en viajar a la Santa Sede para visitar al Santo Padre.

Antes de la reanudación de las relaciones, se hizo presente la resistencia de los protestantes de Estados Unidos, que temían que los 50 millones de católicos del país recibieran mayores privilegios. Sin embargo, el entonces presidente protestante Ronald Reagan vio una oportunidad para facilitar el diálogo con los católicos, en vísperas de las elecciones presidenciales. Muchos grupos protestantes emitieron su queja: veían la reanudación de las relaciones con la Sede Apostólica como una auténtica violación a la constitución, ya que daba a la Iglesia católica una posición privilegiada. Finalmente, con el consenso del Congreso de Estados Unidos, Ronald Reagan nombró a William Wilson, su consejero personal, embajador del país en la Santa Sede. Y en Washington, el primer nuncio apostólico sería el arzobispo italiano Pío Laghi, que se había destacado ya en los tiempos de Pablo VI, cuando era representante de la Santa Sede en Jerusalén, como un fervoroso filopalestino. Fue el protestante Ronald Reagan el que dio el primer paso. Pero mucho había contribuido a ello el viaje apostólico del papa Juan Pablo II a Estados Unidos ${ }^{4}$, donde al entusiasmo de los católicos se sumaron inesperadamente también los aplausos de no pocos protestantes.

El diario oficioso vaticano, L Osservatore Romano, publicaba la noticia con gran relieve en primera página, con fecha de 10 de enero de 1984. Son sólo cinco renglones, pero con peso histórico. A partir de ahí, la Santa Sede y Estados Unidos mantienen relaciones diplomáticas, tras muchos años de desconfianzas recíprocas ${ }^{5}$. El papa Benedicto XVI visitó Estados Unidos de América del 15 al 21 de abril de 2008. La ceremonia de bienvenida se produjo en la Casa Blanca el 16 de abril. La salida del aeropuerto de Fiumicino se producía a las 12,00 horas para llegar a las 16,00 horas, horario local de la base militar de Andrews. La despedida

${ }^{4}$ Cf. A. RicCARDI, II. La biografía, Madrid 2011, pp. 335-336.

5 Cf. Ma Del C. Garcimartín Montero, "Las relaciones diplomáticas entre Estados Unidos y : una aproximación histórica”, en Ma DEL M. MARTín - M. SALIDO - J. M ${ }^{\mathrm{a}}$ VÁzQUez García-PEÑUela (EDS.), Iglesia católica y relaciones internacionales. Actas del III Simposio Internacional de derecho Concordatario, Almería 7-9 de noviembre de 2007, Granada 2008, pp. 393-404. 
sería en avión desde el aeropuerto internacional John Fitzgerald Kennedy de Nueva York hacia Roma y llegó a las 10,45 del lunes 21 de abril a Roma. Un viaje apostólico con un gran contenido y fuerte repercusión. Entre otros aspectos, dirigió un discurso a la Asamblea General de las Naciones Unidas, el viernes 18 de abril.

Las relaciones diplomáticas entre EE.UU. y la Santa Sede, atraviesan un momento importante ya que el presidente Obama hizo su primera visita al papa Francisco el 27 de marzo de 2015. La sintonía entre ambos dignatarios ha desembocado en una amistad personal entre el Santo Padre y el presidente de los EE.UU6.

En la actualidad el presidente Barack Obama ha mostrado reiteradamente mucha admiración pública por el papa Francisco. Cuando el Santo Padre se convirtió en el primer Pontífice latinoamericano de la historia, el presidente norteamericano lo calificó como el paladín de los pobres y de los más vulnerables. El papa Francisco tiene una humildad increíble, un sentido de empatía con los débiles, con los más necesitados y pobres. Posee un gran espíritu, un profundo sentido de amor y caridad que se manifiesta no sólo en lo que dice, sino también en lo que hace. Obama se reunió en el Vaticano con Benedicto XVI, el 10 de julio 2009, seis meses después de su llegada a la Casa Blanca.

El presidente estadounidense, Barack Obama, llegó al Estado de la Ciudad del Vaticano para reunirse por primera vez con el papa y sostener lo que la Casa Blanca calificó como un diálogo franco de asuntos en los que concuerdan y en los que difieren. Obama llegó al Vaticano bajo estrictas medidas de seguridad desde la ciudad italiana de L'Aquila, en donde participaba en la cumbre del Grupo de los Ocho países más industrializados del mundo. Su entrada a la Ciudad del Vaticano se produjo a las 16,00 horas por el Arco de las Campanas, con la comitiva oficial a través de la Plaza de san Pedro. Barack Obama fue conducido hasta el patio de san Dámaso en la explanada del palacio apostólico en donde fue saludado por la guardia de honor. La entrevista, a solas, entre ambos mandatarios, fue durante 40 minutos en el despacho del Pontífice, en el Palacio Apostólico del Vaticano, en el que ha sido el primer encuentro entre los dos jefes de Estado. Obama y Benedicto XVI nunca antes se habían reunido, pese a que el papa fue uno de los primeros en felicitar al presidente estadounidense cuando éste ganó las elecciones en noviembre de 2008.

${ }^{6}$ Cf. J. Nicholson, Estados Unidos y largo camino, en 30 Días 22 (03-2004) 10-12; La edición española de 30 Giorni ha publicado el texto del libro en dos partes, la primera en octubre de 2002: en 30 Días 20 (10-2002) 27-48; y la segunda en febrero de 2004: en 30 Días 22 (02-2004) 54-66. 
El viaje y estancia en los EE.UU. de América, el Santo Padre congregó a multitudes de creyentes y atrajo el sumo interés de muchos no católicos. Tanto en la Casa Blanca, como en el Congreso y en la Asamblea de las Naciones Unidas, el papa pidió luchar contra el cambio climático y más compasión con inmigrantes, pobres y refugiados. En un avión de American Airlines, como establece el protocolo, pues en todos los viajes sale con la compañía bandera italiana, y el regreso se hace con el pabellón del Estado que visita, el Santo Padre despegó desde el Aeropuerto Internacional de Filadelfia rumbo a Roma, tras seis días de visita en EE.UU. y otros tres en Cuba. En la isla caribeña, el papa recibió agradecimientos por ayudar al restablecimiento de las relaciones diplomáticas entre EE.UU. y el gobierno comunista de Cuba. Los guiños realizados por Barack Obama al papa Francisco demostraron su plena sintonía y su máximo agradecimiento, que no pasaron desapercibidos para nadie.

\section{Viaje apostólico a Cuba}

Se trata del décimo viaje del papa Francisco fuera de Italia. El papa se encontró con un país que vive por igual su catolicismo, con los cultos afrocubanos que están enraizados en las religiones que llegaron con los esclavos y el sincretismo de la misma sociedad cubana, lo que supone que muchos de ellos integren sus creencias cristianas con los ritos santeros. En las iglesias y parroquias cubanas se espera el viaje con la confianza y la esperanza para que ayudase especialmente en el refuerzo de sus bases sociales. La comunidad cristiana tiene que crecer de manera espectacular si no quiere sucumbir ante la indiferencia o el propio sincretismo religioso. Quizá Francisco, por medio de su mediación diplomática, es el tercer papa que visita Cuba en diecisiete años, haga lo imposible para buscar la concordia 7 . El viaje para todos, no sólo es apostólico, sino que lleva una carga política, que hace que la diplomacia pontificia, haya puesto todos sus resortes en marcha. La Iglesia cubana provocó un giro en las relaciones con la disidencia. Eso le valió una progresión muy importante respecto, a la renuncia al activismo político. De esta manera la jerarquía católica, recondujo las relaciones con el régimen castrista. Comenzó a acceder a los fondos que llegaban del extranjero; fue recuperando muchas de las propiedades confiscadas a la Iglesia y se ha dado permiso para la cons-

7 Cf. Pablo de Llano, "Los cubanos esperan al papa del deshielo", en El País (1809-2015) 8 . 
trucción de nuevas iglesias ${ }^{8}$. No cabe duda que la Iglesia católica ha seguido volcada en la ayuda en los geriátricos, también en los hospitales y psiquiátricos. Sin embargo no tiene todas las llaves de la catequización, la libertad de los medios de comunicación y la enseñanza privada. Estos son otros temas todavía sin abordar realmente9.

Sin duda la Iglesia católica ha conseguido una mayor consolidación en las dos últimas décadas como una de las mayores instituciones de la sociedad civil cubana. Esto no se hubiera podido dar sin una verdadera interlocución entre la comunidad cristiana y el partido comunista de Cuba. Más allá de las dificultades propias de los mismos entornos, no todos piensan igual al respecto pues mantienen sus posiciones bien atrincherados, lo cierto es que el pacto con el Gobierno de Cuba, ha conseguido una serie de claras ventajas por ambas partes. La vida cristiana se ha incrementado a todos los niveles, pues llevaba más de treinta años languideciendo sistemáticamente. Por otro lado, el régimen castrista tuvo una ayuda, sin esperarlo, por parte de la Iglesia sobre los mismos cristianos, que más allá del adoctrinamiento ateo que mantenían, le hizo ver el sentido trascendente de la propia realidad circundante en la que vivían.

La inveterada diplomacia pontificia llevó a considerar la importancia y magnitud de unas fluidas relaciones entre las partes. Si algo hizo en el deshielo del viaje del papa san Juan Pablo II, a la isla caribeña, fue la necesidad del diálogo permanente con la autoridad competente como máxima expresión de un nuevo tiempo en las tortuosas relaciones entre la Santa Sede y Cuba. Siempre según los postulados de la Doctrina social de la Iglesia, había que preservar la dignidad trascendente de la persona humana. Eso era intocable. Era preciso un nuevo aire que restaurase nuevos tiempos mediante diálogos profundos que llevase a ciertas transacciones de índole y carácter diplomático que condujesen al levantamiento del embargo por parte del gobierno norteamericano y al mismo tiempo reintegrar a la República de Cuba en el gran concierto internacional. Esto debía de llevar a una mayor flexibilización del mismo régimen castrista y tratar de conseguir el reconocimiento de los derechos civiles, políticos y religiosos que, sin duda, llevaría a la Iglesia católica a ser mediadora entre la sociedad y el propio régimen comunista de la

6.

8 Cf. Pablo de Llano, "La Iglesia se reconstruye en la isla”, en El País (19-09-2015)

9 Cf. Juan Jesús Aznárez, "El providencial desembarco de Francisco", en El País (18-09-2015) 8. 
Isla ${ }^{10}$. Las condiciones de vida, aunque siguen siendo lamentables para el pueblo cubano, éstos vislumbran un nuevo amanecer para un próximo futuro. Muchos cubanos ansiaban conseguir un milagro que produjese cambios sustantivos en el interior y mayores cuotas de libertad ${ }^{11}$. Poco más de tres días duró la visita del papa Francisco a Cuba ${ }^{12}$. Tras el saludo protocolario con Raúl Castro y la pautada con su hermano Fidel13 comenzaron las diversas actividades programadas por el viaje ${ }^{14}$. Un viaje cargado de interés mutuo ${ }^{15}$ por el nexo que había supuesto la figura del primer papa latinoamericano, en la reconciliación de Cuba y Norteaméri$\mathrm{ca}^{16}$. La próxima bonanza económica por la inyección de grandes sumas de dólares inundará como el Caribe.

Seguramente veremos con el tiempo el interés de los grandes capitales, especialmente de los Estados Unidos para la reconstrucción de $\mathrm{Cuba}^{17}$. No sólo es cuestión de necesidad, la que obliga, unido a las necesidades del pueblo cubano, sino un acto de auténtica justicia. Es preciso desbloquear el bloqueo norteamericano lo antes posible ${ }^{18}$. Dicha flexibilización se llevó a cabo por Estados Unidos un día antes de la llegada del Santo Padre a Cuba19. La previa liberalización de presos comunes, que fue aproximadamente de 3.500, igualmente previa a la llegada del Pontí-

10 Cf. Rafael Rojas, "Esperando a Francisco”, en El País (18-09-2015)13.

11 Cf. Darío Menor, "Las Damas de Blanco: Necesitamos un milagro suyo para que Cuba cambie", en La Razón (20-09-2015) 17; CARMEN MuÑoz, "Los cubanos confían en que Francisco obre un milagro en la Isla", en $A B C$ (20-09-2015) 60.

12 Cf. Mónica Bernabé, "La vida seguirá igual tras el papa", en El Mundo (19-092015) 27-27.

13 Cf. Juan Vicente Boo, "Cuarenta minutos con Fidel", en $A B C$ (21-09-2015) 4445; Darío Menor, "Una cita familiar con Fidel", en La Razón (21.09-2015) 39; Mónica Bernabé, "El papa Che en el epicentro de la revolución", en El Mundo (21-09-2015) 26; Pablo Ordaz, "Francisco visita a Fidel", en El País (21-09-2015) 7

14 Cf. Andrés Beltramo Álvarez, "Cuba debe florecer, con la ayuda de Francisco", en Alfa y Omega 943 (17-09-2015) 6.

15 Cf. Rafael Navarro-Valls, "La difícil facilidad de un viaje", en El Mundo (2009-2015) 29 .

16 Cf. Juan Vicente Boo, "Francisco anima a Cuba y a EE. UU. a seguir por el camino de la reconciliación", en $A B C$ (20.09-2015) 58-59; Darío MEnOR, "El papa pide la reconciliación para evitar una Tercera Guerra Mundial", en La Razón (20-09-2015) 14-15; Mónica BernAbÉ, "Un papa para abrir Cuba al mundo", en El Mundo (20-09-2015) 28; PABLo ORDAZ, "El papa llega a Cuba a poyar el acercamiento a EE. UU.", en El País (2009-2015) 1 y 6.

17 Cf. José Luis Peñalva, “Una Cuba cañíi”, en El Diario Montañés (19-09-2015) 39.

18 Cf. Milagros López de Guereño, "Cuba espera el milagro de Francisco", en El Diario Montañés (19-09-2015) 38-39; Gina Montaner, "Milagro en Cuba", en El Mundo (19-09-2015) 27.

19 Cf. Silvia Ayuso, “EE. UU. suaviza las restricciones”, en El País (19-09-2015) 6. 
fice a La Habana ${ }^{20}$. Era un reconocimiento a la labor realizada por el papa Francisco, en el impulso de las negociaciones entre ambas partes, para conseguir el restablecimiento diplomático con todo lo que ello suponía. Esto llevaba a convertir dicho viaje en histórico, sin precedentes, por las repercusiones en la política internacional ${ }^{21}$ y la necesidad de intermediación entre todas las partes afectadas 22 . El diálogo se había forjado con san Juan Pablo II, Benedicto XVI y culminaba con Francisco ${ }^{23}$. Los tres ${ }^{24}$. Pero bien mirado, pues el hecho de la superación del embargo, de manera íntegra sería decisivo para propiciar una mayor apertura del propio régimen, desde el punto de vista de la libertad y del conjunto de los derechos humanos. Por eso los posibles encuentros con la disidencia, no desmentidos ni confirmados en principio, abren las distintas expectativas y opciones. Pero Francisco optó por la calle del medio, al no establecer líneas claras en este tema y que al final resultaron fallidas, manifestando que no se encontraban en el programa previsto. Estaba claro que el papa Francisco no quería entorpecer la buena sintonía con Raúl Castro. Pero las veladas críticas ${ }^{25}$ al régimen cubano fueron contestadas con detenciones de la disidencia ${ }^{26}$ cerca de los actos públicos del papa Francisco $^{27}$. Sin duda, el papa ha procurado mediar en todo momento, pero al mismo tiempo proceder a implantar un nuevo orden en Cuba, e incluso llevando los ideales de la revolución; no la del castrismo sino la Jesucristo ${ }^{28}$. Para ello siempre fue necesario contar con la Iglesia cubana y el

20 Cf. Javier Ansorena, "EE.UU. flexibiliza el embargo a Cuba un día antes de la llegada del papa", en $A B C$ (1909-2015) 38; PABLO PARDo, "EE. UU. da otro paso para desmantelar el embargo", en El Mundo (19-09-2015) 26-27.

21 Cf. DARío Menor, "La palabra del papa llega a Cuba a través del USB", en La Razón (1909-2015) 42-43; PABLO ORDAZ, "El papa inicia en Cuba una visita política e imprevisible", en El País (19-09-2015) 6.

22 Cf. INOCENCIO ARIAs, "El papa en Cuba. La intermediación política, en La Razón (20-09-2015) 22.

23 Cf. Jaime Lucas Ortega, cardenal arzobispo de La Habana, "En el corazón de la gente", en La Razón (20-09-2015) 18-19.

24 Cf. Fran Otero, "La Isla de los tres papas", en La Razón (20-09-2015) 20.

25 Cf. JuAN VICENTE Boo, "El papa a los cubanos: No se sirve a las ideas. Se sirve a las personas", en $A B C$ (21-09-2015) 46-47; DARío MENOR, "No se sirve a las ideas, se sirve a las personas", en La Razón (21-09-2015) 40-41;

26 Cf. Darío Menor, "Detenidas tres personas para evitar un encuentro con el papa", en La Razón (21-09-2015) 38-39; PABLO ORDAZ, "El papa evita cualquier referencia a los disidentes en su primer acto en Cuba", en El País (21-09-2015) 7.

27 Cf. CARMEN MUÑOZ, "El régimen impide el encuentro de Francisco con tres opositoras", en $A B C$ (22-09-2015) 43.

28 Cf. Pedro Miguel Lamet, “La otra revolución”, en El Mundo (21.09-2015) 27. 
mejor posicionado ha sido siempre el cardenal arzobispo de La Habana, Jaime Lucas Ortega, que con sus 78 años seguía al frente de la misma ${ }^{29}$. Los reemplazos, no siempre son fáciles de solucionar, cuando se trata de regímenes con sabor dictatorial, donde es preciso calibrar muchos factores que influyen poderosamente en la buena comunicación entre las partes.

El escenario elegido por el papa para hablar, siempre veladamente sobre la disidencia, fue la ciudad de Holguín. En la homilía, tras dirigirse a la patrona de Cuba, la Virgen de la Caridad del Cobre, Francisco lanzó un llamamiento por medio de la mirada de la Patrona, diciendo "a Ella le pido que mantenga sobre todos y cada uno de los hijos de esta noble nación su mirada maternal y que esos «sus ojos misericordiosos» estén siempre atentos a cada uno de ustedes, sus hogares, sus familias, a las personas que pueden estar sintiendo que para ellos no hay lugar" 30 , de los cubanos, en alusión manifiesta a una disidencia que se queja por no haber sido recibida por el Santo Padre. Sin duda, como ciudad elegida por el papa por ser la cuna de los hermanos Castro Ruz ${ }^{31}$, que es a la vez uno de los centros de la cristiandad más antiguos de $\mathrm{Cuba}^{32}$, pero que al mismo tiempo servía como trampolín mediático, fuera de la oficialidad que siempre ata como podía ser en este caso La Habana. Pero no todos han sabido ver y comprender tales insinuaciones como críticas más enmascaradas ${ }^{33}$. Ciertamente, muchos esperaban una acción más directa del Pontífice, pero no han querido comprender los hilos con los que la Iglesia, en este caso la Santa Sede, sabe hilar muy fino, todo lo que la veterana diplomacia pontificia consigue llevar adelante ${ }^{34}$. 2015) 26-27.

29 Cf. Ángel Tomás GonzÁlez, "El cardenal del deshielo", en El Mundo (21-09-

30 Cf. http://w2.vatican.va/content/francesco/es/homilies/2015/documents/papa-francesco_20150921_cuba-omelia-holguin.html Visto 12-10-2015.

31 Cf. José Manuel Vidal - Ángel Tomás González, "El papa, en la cuna de los Castro", en El Mundo (22-10-2015) 17.

32 Cf. Milagros LóPez de Guereño, "El papa exalta a la Iglesia de Cuba", en El Diario Montañés (22-09-2015) 36.

33 No resulta fácil poder contentar siempre a todos. Los viajes apostólicos tiene un fuerte componente evangelizador y una profunda dimensión espiritual. Sin duda, el papa Francisco ha querido dejar suaves y penetrantes lloviznas, mejor de provocar chaparrones fuertes que podrían descarrilar las buenas relaciones existentes entre el régimen y la Iglesia cubana.

34 Cf. Milagros López de Guereño, "El papa exalta a la Iglesia de Cuba", en El Diario Montañés (22-09-2015) 36. 
También fue contundente el encuentro con los jóvenes, el día anterior en la capital, al plantearles los ideales de vivir desde la esperanza. "Pero, ¿qué hacer? ¿Cómo hallar caminos de esperanza en la situación en que vivimos? ¿Cómo hacer para que esos sueños de plenitud, de vida auténtica, de justicia y verdad, sean una realidad en nuestra vida personal, en nuestro país y en el mundo? Pienso que hay tres ideas que pueden ser útiles para mantener viva la esperanza. La esperanza, un camino hecho de memoria y discernimiento; La esperanza, un camino acompañado; La esperanza, un camino solidario ${ }^{35}$. El llamamiento a los jóvenes suponía una mirada a que Cuba debía de florecer con ayuda puesta en el Señor de la Vida y la esperanza ${ }^{36}$. Fue una llamada a un tiempo nuevo, un tiempo marcado por la reconciliación nacional, para que todos tengan en cuenta a todos. Sin distinciones, sin diferencias, sin discriminaciones. El pueblo cubano está llamado a saber capitalizar todo el viaje apostólico a Cuba del papa Francisco, al igual que supo comprender la infinidad de pasos realizados tras los viajes papales anteriores, de san Juan Pablo II y Benedicto XVI ${ }^{37}$. Todos llevaron a nuevas pistas de actuación de tal manera que el pueblo cubano, tan religioso, pudiera dar mayores pasos en su discernimiento social, económico y espiritual. Por eso Francisco ha abogado por el camino del diálogo permanente, que ha llevado muy bien la jerarquía cubana, con el apoyo de la Santa Sede y las magníficas posibilidades que le ha brindado el régimen. "Que no sepa tu mano izquierda lo que hace tu derecha"38. La acción de Francisco se ha desarrollado tratando de evitar, aquellas críticas directas ${ }^{39}$, sobre las condiciones de vida de los cubanos, que según el criterio de análisis político que se aplique, no deja de ser un tanto desilusionante, dado las críticas vertidas por el Santo Padre sobre el capitalismo. No cabe duda que la apuesta de Francisco no es tanto a corto plazo sino más bien a largo plazo ${ }^{40}$. Para otros sectores, el papa, no hizo ningún tipo de alusiones a las discrepancias con el régimen tras tres días de estancia en la Isla caribeña. Parecía no haber

35 Saludo y encuentro del Santo Padre con los jóvenes en el Centro cultural Padre Félix Varela de Ha Habana. Cf. http: //w2.vatican.va/content/francesco/es/speeches/2015/ september/documents/papa-francesco_20150920_cuba-giovani.html Visto 12-10-2015.

36 Cf. Darío Menor, "Los jóvenes dieron voz a la disidencia ante el papa", en La Razón (22-10-2015) 42-43.

37 Cf. Antonio Pelayo, "Siembra de esperanza en Cuba", en Vida Nueva 2955 (1218-09-2015) 23-30 Pliego.

38 Mt. 6,1-8.

39 Cf. PABlo Ordaz, "El papa más silencioso en Cuba", en El País (22-10-2015) 8.

40 Cf. Ignacio Uría, "El renacer de la Iglesia cubana", en $A B C$ (22-09-2015) 43. 
alusiones a la falta de las mínimas libertades para el desarrollo de la vida social y política ${ }^{41}$.

En Santiago de Cuba en el santuario de la Virgen de la Caridad del Cobre, en la homilía el Santo Padre abogó manifestando: "Nuestra fe, nos saca de casa para visitar al enfermo, al preso, al que llora y al que sabe también reír con el que ríe, alegrarse con las alegrías de los vecinos. Como María, queremos ser una Iglesia que sirve, que sale de casa, que sale de sus templos, que sale de sus sacristías, para acompañar la vida, sostener la esperanza, ser signo de unidad de un pueblo noble y digno. Como María, Madre de la Caridad, queremos ser una Iglesia que salga de casa para tender puentes, romper muros, sembrar reconciliación. Como María, queremos ser una Iglesia que sepa acompañar todas las situaciones embarazosas de nuestra gente, comprometidos con la vida, la cultura, la sociedad, no borrándonos sino caminando con nuestros hermanos, todos juntos. Todos juntos, sirviendo, ayudando. Todos hijos de Dios, hijos de María, hijos de esta noble tierra cubana" "2. Esto clarificaba, a quién quería ver, oír y entender la postura del Santo Padre ${ }^{43}$, ante las condiciones de vida, social, política y económica de Cuba, bajo un régimen comunista, en sus esencias, pero que ya desde la misma visita de san Juan Pablo II, hacía aguas por los cuatro costados. Hacía casi una década que había caído el Muro de Berlín, y con él se llevó a todos los sistemas marxistas de Europa del Este, capitaneados por la Unión Soviética. A duras penas el régimen cubano pudo aguantar si no es por las aportaciones de la Venezuela bolivariana de Hugo Chávez. Pero eso, en la actualidad se ha invertido definitivamente en contra de los Castro.

La Iglesia quiere ante todo, decía Francisco en su acto de despedida en Santiago de Cuba, hacer un llamamiento para sembrar la reconciliación y con un mensaje de que desea y quiere tender puentes y romper muros. Clara alusión del contenido de la visita y el propósito y finalidad del viaje papal. Se buscó ante todo el encuentro como misión ${ }^{44}$.

Así todo, no hubo en ningún momento, referencias explicitas a la realidad del ejercicio de los derechos humanos y libertades en la socie-

41 Cf. JuAn Vicente Boo, "El papa evita en su tercer día en Cuba cualquier alusión a la falta de libertades", en $A B C(22-10-2015)$ 42-43.

42 Cf. http://w2.vatican.va/content/francesco/es/homilies/2015/documents/papa-francesco_20150922_cuba-omelia-santiago.html Visto 12-10-2015.

43 Cf. D. Chimeno - Á. Mengis, "Un enérgico Francisco visita Cuba y Estados Unidos", en Palabra 651(octubre 2015) 20-24.

44 Cf. Antonio Pelayo, "Misionero del encuentro", en Vida Nueva 2957 (26-02-102015) 23-30. 
dad cubana; tampoco se ha llevado a cabo ninguna reunión con disidentes, que habían denunciado continuos arrestos y detenciones durante los días que duró la visita del papa Francisco, especialmente para impedir que los miembros de la oposición al régimen se pudieran acercar a las misas u otras celebraciones litúrgicas del Santo Padre en Cuba. Pero, sin duda, es necesario volver la mirada para entender el significado del viaje desde la perspectiva papal, y teniendo en cuenta siempre la visión diplomática de la Sede Apostólica. Se trata del discurso del Santo Padre en la ceremonia de bienvenida, el 19 de septiembre, en el aeropuerto José Martí de La Habana:

"Desde hace varios meses, estamos siendo testigos de un acontecimiento que nos llena de esperanza: el proceso de normalización de las relaciones entre dos pueblos, tras años de distanciamiento. Es un proceso, es un signo de la victoria de la cultura del encuentro, del diálogo, del «sistema del acrecentamiento universal... sobre el sistema, muerto para siempre, de dinastía y de grupos», decía José Martí. Animo a los responsables políticos a continuar avanzando por este camino y a desarrollar todas sus potencialidades, como prueba del alto servicio que están llamados a prestar en favor de la paz y el bienestar de sus pueblos, y de toda América, y como ejemplo de reconciliación para el mundo entero" 45 .

El proceso de normalización en las relaciones entre EE.UU. y Cuba, gracias a la intermediación del papa Francisco y la labor inveterada de la Santa Sede a favor de todos los hombres y de sus pueblos

Francisco ha ido sembrando una serie de mensajes, de manera especial, en defensa de la reconciliación, sobre la cultura del encuentro y la amistad social; ha instado a los cubanos a servir a las personas y no a las ideas y ha llamado a la Iglesia y a los religiosos a que sean pobres y misericordiosos y dediquen sus vidas a los que denominó los más pequeños, los descartes de la sociedad.

El papa salió de Cuba rumbo a Estados Unidos pasado el mediodía de este martes, de nuevo a bordo del Airbus 330-200, de Alitalia, desde el aeropuerto Antonio Maceo de Santiago de Cuba, tras ser despedido con un largo apretón de manos al pie de la escalerilla del avión por el presidente Raúl Castro Ruz, vestido de guayabera blanca, y conversando con

45 Discurso del Santo Padre. Cf. http://w2.vatican.va/content/francesco/es/speeches/2015/september/documents/papa-francesco_20150919_cuba-benvenuto.html Visto 12-10-2015. 
él de manera animada y desenfadada. No hubo discursos pero una Guardia de Honor sí interpretó los acordes de los himnos de Cuba y de la Santa Sede.

Pero la pregunta que resuena en los oídos de muchos, sean cubanos o no es ¿Qué ocurrirá tras el viaje del Francisco a Cuba? Esa era la cuestión que se hacían muchos tanto dentro como fuera del país, y que entre todos parecía haber consenso de que el viaje apostólico del Santo Padre redundaría positivamente en muchos temas para los cubanos.

La consecuencia más esperada es que el papa Francisco siguiera intercediendo en favor de las relaciones diplomáticas entre Cuba y Estados Unidos, hasta que se consiga la eliminación del embargo o bloqueo social, económico, financiero y comercial impuesto por Norteamérica hace más de 50 años. Otros se inclinaban a pensar que realmente la visita traería una mayor esperanza para todo el pueblo cubano y las mejores expectativas de su calidad de vida que se vería reforzada tras la visita del Santo Padre. Eso, veremos, con el tiempo si se avanza en los límites a la libertad y en el ejercicio de los derechos humanos. Todavía es muy pronto para ver resultados palpables y visibles. Lo que no consiga la diplomacia pontificia, no lo consigue nadie. Sólo que hay que esperar tiempo.

Durante su viaje hacia los Estados Unidos de América, en la rueda de prensa en el avión, el papa reconoció que no había tenido conocimiento de los arrestos de disidentes"4. "Santo Padre, buenas tardes. Soy Rosa Flores de la CNN. Hemos oído que más de 50 disidentes han sido arrestados fuera de la Nunciatura porque trataban de tener un encuentro con usted. La primera pregunta es: ¿Le gustaría encontrarse con los disidentes? Y si tuviera lugar dicho encuentro, ¿qué les diría?"

"Primero, no tengo noticias de que haya sucedido eso. No tengo ninguna noticia, lo cual quiere decir, ¿sí?, ¿no?, no sé. Directamente, no sé. $Y$ sus dos preguntas son futuribles. ¿Me gustaría... qué sucediera? A mí me gusta encontrarme con toda la gente porque considero que, primero, toda persona es hijo de Dios, tiene derecho. Y segundo, siempre un trato con otra persona enriquece. $O$ sea, que al futurible lo respondo así. Me gustaría encontrar con todo eso. Si usted quiere que hable algo más de los disidentes, le puedo decir algo, sí, bien concreto: de la

46 Cf. JUAN ViCENTE Boo, "Francisco: No tuve noticia del arresto de disidentes cubanos", en $A B C$ (23-09-2015); DARío Menor, "Obama se replantea el embargo a Cuba antes de recibir al papa", en La Razón (23-09-2015) 38-39; MónICA BERnABÉ, "Ni libertad ni derechos humanos", en El Mundo (23-09-2015) 25; PABLo ORDAZ, "Francisco admite que nunca pensó reunirse con los disidentes cubanos", en El País (23-09-2015) 6. 
Nunciatura, primero, estaba bien claro que yo no iba a dar audiencia, porque se pidieron audiencias, no sólo los disidentes, sino también audiencias de otros sectores, incluso de algún Jefe de Estado distinto. Yo estoy en una visita en un país y solamente a eso. O sea que no había prevista ninguna audiencia ni con los disidentes ni con otros. $Y$, segundo, de la Nunciatura se hicieron llamadas telefónicas a algunas personas que están en esos grupos disidentes. El encargo del Nuncio era comunicarles que yo, con gusto, cuando llegara a la Catedral para el encuentro con los consagrados, saludaría a los que estaban allí. Un saludo. Eso sí existió. Ahora bien, como ninguno se identificó en el saludo, yo no sé si estaban o no estaban. Yo saludé sobre todo a los enfermos, a los que iban en silla de ruedas... Pero ninguno se ha identificado como disidente. Desde la Nunciatura se han hecho algunas llamadas para invitarles a un saludo de pasada...”.

Más adelante se le volvió a preguntar: Nelson Castro, de "Radio Continental", que viene de Argentina... Buenas tardes, Santo Padre. La pregunta vuelve sobre el tema de la disidencia, en dos aspectos: ¿Por qué se ha decidido no recibir a los disidentes? Y segundo: Ha habido uno que se le ha acercado y que ha sido apartado y arrestado... La pregunta es: ¿Desempeñará la Iglesia católica un papel en la búsqueda de una apertura a las libertades políticas, visto el papel desempeñado en el restablecimiento de las relaciones entre Cuba y los Estados Unidos? Este tema de las libertades, que es un problema para quienes piensan diversamente en Cuba, ¿será una tarea primordial que la Santa Sede piense en el devenir de la Iglesia católica en el futuro de Cuba? ${ }^{47}$.

"Primero, "los", no "recibirlos". No, no recibí ninguna audiencia privada. Eso para todos. Y hubo una de un Jefe de Estado y se le dijo que no, y no tenía nada que ver con los disidentes. $O$ sea, el trato con los disidentes fue el que expliqué. La Iglesia acá, la Iglesia de Cuba, hizo un trabajo de listas de indultos. Fueron indultados 3.500 por ahí -la cifra me la dijo el Presidente de la Conferencia Episcopal-... sí, más de tres mil. Y todavía hay casos en estudio. Y la Iglesia aquí, en Cuba, está trabajando para conseguir indultos. Por ejemplo, alguno me ha dicho: "Sería bonito terminar con la prisión de por vida, la cadena perpetua". Hablando claramente, la cadena perpetua es casi una pena de muerte disimulada. Esto lo he dicho públicamente en un discurso a los juristas europeos. Tú estás ahí, muriendo cada día sin esperanza de liberación.

47 Cf. Pedro Ontoso, "Diplomacia entre líneas", en El Diario Montañés (23-092015) 39 . 
Es una hipótesis. Otra hipótesis es que se otorguen indultos generales cada uno o dos años... Pero la Iglesia está trabajando, ha trabajado... No digo que estos más de tres mil hayan sido liberados por las listas de la Iglesia, no. La Iglesia ha elaborado una lista -no sé de cuantas personas-, ha pedido oficialmente indultos y seguirá haciéndolo"48.

No cabe duda, que el papa Francisco se ha ido adecuando a los protocolos de la Santa Sede. No en todo, pues es notorio su desapego constante por lo establecido por la Curia romana, en el contexto de la administración vaticana, pero no se puede sustraer a las condicionantes reglas de su diplomacia. A veces no queda otro remedio, si es para conseguir sus objetivos. Francisco hizo todo lo posible para que la maquinaria pontificia se pusiera a trabajar con el máximo interés por conseguir un acercamiento, primero y posteriormente una profunda negociación para llevar a cabo uno de sus mayores éxitos. El reconocimiento mutuo entre ambos países. Cuba y EE. UU. Para ello llevó con todas sus fuerzas el empeño y consiguió no sólo el acercamiento entre ambas partes sino que se produjera el establecimiento pleno de relaciones diplomáticas y se dispusiera tanto en La Habana como en Washington de las respectivas embajadas, al frente de sus embajadores plenipotenciarios. Los pasos eran evidentes y la necesidad de exteriorizarlos quedaba patente por ambas administraciones. Todo esto se había llevado a cabo, previamente a la gira pastoral de Francisco, que unió a los dos países en su décimo viaje apostólico. Las suertes quedaban echadas.

El hecho de haber podido encarrilar las relaciones entre Cuba y Estados Unidos, en las que la Santa Sede, la diplomacia vaticana y el mismo papa Francisco, bien merecían no encallar con el buque de la disidencia. Por eso la geopolítica del papa Francisco llevaba el sello de un viaje muy comprometido y delicado en todos sus aspectos. Es preciso recordar que entre todos los presos excarcelados no hay ninguno de carácter político o disidente del régimen. El orden desarrollado por la geopolítica ya apareció claramente durante el viaje de san Juan Pablo II ${ }^{49}$, en 1998. Posteriormente bajó su perfil en el pontificado de Benedicto

48 Se puede ver completo en la rueda de prensa ofrecida por el Santo Padre en el avión que le llevaba a Washington Cf. http://w2.vatican.va/content/francesco/es/speeches/2015/september/documents/papa-francesco_20150922_intervista-santiago-washington.html Visto 12-10-2015.

49 Cf. EMILI J. Blanco, "El papa que facilitó el deshielo de la última guerra fría”, en $A B C$ (20-09-2015) 59; Ángel TOMÁs GONZÁLEz, "La operación crucifijo de Fidel", en $E l$ Mundo (20-09-2015) 28-29; Darío Menor, "Una Iglesia que resistió el ateísmo de Estado", en La Razón (20-09-2015) 16-17. 
XVI, a pesar del viaje realizado en 2012. Pero volvió a su punto cenital con la llegada a la sede de Pedro por el Santo Padre Francisco ${ }^{50}$. No cabe duda, que el prestigio recogido brillantemente por el Sumo Pontífice, servirá para acentuar un mayor fortalecimiento de las relaciones entre la Santa Sede, en definitiva de la Iglesia católica cubana, con el régimen castrista imperante en la Isla. Seguro que pasado algún tiempo, atisbaremos nuevos amaneceres.

\section{Viaje apostólico a los Estados Unidos de América}

La llegada a Washington venía precedida por un minucioso y detallado programa que había sido estudiado con lupa. No se había dejado nada a la improvisación. No era el estilo curial, ni tampoco de la Santa Sede, que cuida siempre hasta los más pequeños e insignificantes pormenores. Las opiniones del papa podían dividir a la opinión pública norte americana ${ }^{51}$. Pero era necesario afrontar diversos temas entre EE. UU., y la Santa Sede, pues en este momento las relaciones atravesaban un momento dulce ante la buena sintonía entre ambos Jefes de Estado: Francisco y Barack Obama ${ }^{52}$. El viaje creaba una máxima expectación a todos los niveles. El papa recién llegaba de su viaje a Cuba, sus anteriores destinos habían sido siempre naciones periféricas, en el contexto mundial y sin demasiada importancia para los grandes y poderosos. Esta vez incluía, a Washington, Nueva York y Filadelfia, que poseían por sí mismas y con una gran carga geopolítica. El menú estaba en la carta y había que servirlo. El Santo Padre no podía ni debía esquivar los problemas y tampoco podía pasar desapercibido. También sabía perfectamente que tendría, como de costumbre, quienes aceptarían de buen grado toda su enseñanza como los detractores que no quisieran ni verles ni escucharle. La crítica al sistema económico, imperante en medio mundo, que excluye y margina y no tiene en cuenta la dignidad de la persona, sería constantemente un tema muy beligerante. Un papa que se dirigiría con un discurso

\footnotetext{
50 Cf. Pedro Ontoso, "La geopolítica del canciller Francisco", en El Diario Montañés (20-09-2015) 44-45.

51 Cf. MAnuel Erice, "Las opiniones del papa dividen a la clase política norteamericana, en $A B C$ (23-10-2015) 45; DARío MENOR, "Obama se replantea el embargo a Cuba antes de recibir al papa", en La Razón (23-09-2015) 38-39.

52 Cf. MARC BASSETS, "El papa latino afronta en EE. UU. la pujanza evangélica", en El País (23-09-2015) 6; PABlo PARdo, "El vía crucis del papa en Estados Unidos", en El Mundo (23-09-2015) 24-25.
} 
a las dos Cámaras del Congreso norteamericano, lo que hacía subir de manera inconmensurable las expectativas ante tal acontecimiento. Igualmente la recepción oficial en los jardines de la Casa Blanca, se encontrarían repletos de personas ávidas de su visita a los Estados Unidos de América, con más de 15.000 invitados. Después vendría el encuentro personal con el presidente Obama. Por último, serían muchos Jefes de Estado y de Gobierno, entre otros, que vendrían a escucharle, un discurso en español, ante un pleno de la Organización de las Naciones Unidas, en el famoso Palacio de Cristal de Nueva York ${ }^{53}$. ¿Se podía pedir más cosas a un papa que había revolucionado a la Iglesia católica, en tan poco tiempo de pontificado?

El papa Francisco mantuvo la atención de todo el país desde el primer momento de su llegada a la Base militar de Andrews, el 22 de septiembre a las 16,00 horas hasta su salida desde Filadelfia hacia Roma, el domingo 27 a las 20,00 horas, seis días más tarde. Acaparó todas las cámaras de televisión con gestos y mensajes de todo tipo. Unos más simbólicos, otros más cercanos y otros más duros por su contenido. Uno de los aspectos que más se destaca es la coherencia entre cómo vive y qué cree; la lucha continua contra el flagelo de la pobreza, su forma llana y directa para hablar de cualquier tema por escabroso que pueda ser; el objetivo de conseguir para la Iglesia norteamericana un balón de oxígeno ante el problema de los abusos sexuales, auténtico escándalo, descubiertos en el año 2002. Tema que fue descubierto y puesto a la luz pública con el papa emérito Benedicto XVI, pero que tuvo que afrontar con toda su crudeza, Francisco. Con toda seguridad el papa recibirá a algún grupo de víctimas de tales abusos, que suavizará la tensión existente por parte de la sociedad americana. Su visita dejó sin palabras a muchos de sus opositores. Ha producido no sólo una gran expectación sino una gran ola de cariño, confianza y esperanza para toda la humanidad, tendiendo puentes, abriendo nuevos caminos y retomando la misericordia de Dios.

El Santo Padre Francisco llegó a la Base aérea de Andrews de la Fuerza Aérea, en Meryland, en el vuelo de las líneas aéreas italianas, Alitalia, procedente de Santiago de Cuba, tras el término del viaje a Cuba. Esperaba al pie de la escalerilla del avión, el presidente Barack Obama y su familia, su esposa Michelle y sus hijas. El papa descendió la escalinata y pisó suelo norteamericano por primera vez en su vida. Esperaban tam-

53 Cf. Andrés Beltramo Álvarez, "Estados Unidos: un viaje minuciosamente preparado", en Alfa y Omega 943 (17-09-2015) 10. 
bién junto a la escalerilla, los miembros de la jerarquía católica y cosa inusual, se encontraba allí el vicepresidente, Joe Biden.

El paso previo de Francisco por Cuba antes de llegar a Norteamérica fue un acto para intentar acercar mucho más a ambos países y acortar y limar las diferencias existentes todavía. Obama siempre puso de manifiesto la humildad, simplicidad y gentileza de las palabras del papa, Francisco trataría de demostrar, que ninguna de esas cualidades le restaban lo más mínimo para expresar en todo momento lo que tenía que decir. Es necesario dar otros pasos más valientes que lleven al fin del embargo impuesto por Estados Unidos y que no depende del Presidente Barack Obama sino más bien del Congreso norteamericano ${ }^{54}$. El programa desarrollado por Francisco en los Estados Unidos fue igualmente muy intenso. El Santo Padre Francisco llegó el martes 22 de septiembre a Washington, y fue recibido, el miércoles 23, a primera hora en la Casa Blanca por el presidente Barack Obama. A continuación mantuvo el encuentro con los obispos de EE.UU. en la catedral de san Mateo en Washington. Por la tarde celebró la Eucaristía, en la que se canonizó al beato Fray Junípero Serra en el santuario de la Inmaculada Concepción en Washington. Inesperadamente después de la misa, el papa se trasladó a visitar la residencia de las Hermanitas de los Pobres ${ }^{55}$. El jueves 24 fue recibido por el Congreso de EEUU, donde pronunció un discurso, para luego visitar el Centro Caritativo de la parroquia de San Patricio y mantener un encuentro con los indigentes. Más tarde se trasladó al aeropuerto JFK de Nueva York y donde acude al rezo de vísperas con el clero, religiosos y religiosas en la catedral de san Patricio. El viernes 25 acude a primera hora de la mañana a la sede de la Organización de las Naciones Unidas, donde pronuncia un discurso, para celebrar luego un encuentro interreligioso en el Memorial de la Zona Zero de Nueva York. Por la tarde gira una visita a la escuela Nuestra Señora Reina de los Ángeles y encuentro con los niños y familias inmigrantes en Harlem y terminar con la celebración de la misa en el Madison Square Garden.

El sábado 26, llega a Filadelfia, celebra la Eucaristía con los obispos y religiosos de Pensilvania en la catedral de san Pedro y san Pablo. Por la tarde acude al encuentro por la libertad religiosa con la comunidad hispana y otros inmigrantes en el Independence Mall de Filadelfia. Por últi-

54 Cf. Mercedes Gallego, "El papa se presenta en EE. UU. como hijo de inmigrantes", en El Diario Montañés (24-09-2015) 36-37.

55 Cf. Darío Menor, "Francisco pone a América frente al espejo", en Vida Nueva 2958 (03-09-10-2015) 8-13. 
mo participa en la Fiesta de las Familias y vigilia de oración en el Franklin Parkway. El domingo 28 comienza con un encuentro con las víctimas de abusos sexuales, a primera hora de la mañana, en el seminario san Carlos Borromeo y posteriormente enlaza con la visita de los obispos invitados al encuentro Mundial de las Familias en el mismo seminario. A continuación visita a los detenidos en el Centro Correccional CurranFromhold. Por la tarde celebra la misa en la clausura del VIII Encuentro Mundial de las Familias en el Franklin Parkway. Por último saluda al Comité organizador, a los voluntarios y benefactores en el mismo aeropuerto. El viaje oficial del Santo Padre finaliza con la despedida que parte desde el aeropuerto de Filadelfia hacia Roma, donde llegaría en la mañana del lunes 28 de septiembre. El papa se había enfrentado al viaje más largo, intenso y especialmente político.

De esta manera el recibimiento en la Casa Blanca fue apoteósico. Se presentó como hijo de emigrantes y la respuesta del presidente Barack Obama le contestó que recibía al emperador de la Paz. El papa con su estilo tranquilo, amable, sencillo, directo y humilde se ganó inmediatamente no sólo al pueblo norteamericano sino también a todas las grandes cadenas de televisión y medios de comunicación nacionales como internacionales. Tras la ejecución de los himnos nacionales, presenció el desfile de época y las palabras del presidente Obama. Éste reconoció, entre otras cosas la labor de promoción social que lleva adelante la Iglesia católica. Hizo igualmente hincapié en la normalización de las relaciones diplomáticas entre su país y Cuba, labor incansable del mismo Pontífice y la Santa Sede. Francisco utilizó el famoso Good morning, antes de comenzar su discurso. El papa solicitaba a todo el pueblo norteamericano a buscar la construcción de una sociedad verdaderamente tolerante e inclusiva. Las palabras fueron escuchadas en los jardines de la Casa Blanca por más de 15.000 invitados ${ }^{56}$, además de los que lo siguieron por los medios de comunicación ${ }^{57}$.

La recomposición de las relaciones entre los pueblos era esencial para el buen entendimiento de las sociedades y de los pueblos. Manifestó

56 Cf. Mercedes Gallego, "Los incómodos invitados de Obama”, en El Diario Montañés (19-09-2015) 39.

57 Cf. JuAn Vicente Boo, “Obama agradece a Francisco su apoyo al nuevo comienzo entre EE.UU y Cuba", en $A B C$ (24-09-2015) 50-51; DARÍo MENOR, "El papa y Obama se alían contra el cambio climático", en La Razón (24-09-2015) 44-45; PABLO PARDO, "El papa reedita el efecto Obama en Washington", en El Mundo (24-09-2015) 26; PABLO ORDAZ - MARC BASSETS, "Obama y el papa exhiben su sintonía en ecología y migración", en El País (24-09-2015) 6. 
la importancia de la defensa de la libertad religiosa, que sigue siendo uno de los valores del patrimonio más esenciales de Norteamérica para cosechar un inmenso aplauso al referirse a los problemas medioambientales y el cambio climático y los elogios vertidos en este sentido al plan del presidente Barack Obama. Podía esperarse un recibimiento espectacular por parte de la Administración americana pero el hecho es que se convirtió en una apoteosis permanente a través de las calles, cuando pasaba el Fiat 500 negro o cuando sus desplazamientos eran más evidentes con el papamóvil. Pero sí habría algo que destacar sobre el resto, fue la gran compenetración que tuvo el presidente con el Santo Padre en todo momento. La forma del recibimiento a pie de escala en la base aérea de Andrews. La recepción oficial del recibimiento en la Casa Blanca, el mismo discurso. Se notaba la excelente sintonía entre ambas partes. El papa era, es y será un ejemplo viviente para todos ${ }^{58}$. A continuación se produjo el encuentro con los obispos de los Estados Unidos en la catedral de san Mateo de Washington. La cercanía fue muy clara y sus palabras también. No venía juzgar a nadie, sino hacerles reflexionar sobre lo ocurrido y los caminos que han de seguirse en el futuro. Hacer de la Iglesia un hogar humilde y dejar de lado los discursos duros y a veces beligerantes. La Iglesia era madre y debía saber acoger a todos sus hijos. El ministerio episcopal habría de estar en todo momento al servicio de la unidad eclesial y de la maternidad que engendra y hace crecer a sus hijos. Sobre los abusos sexuales a menores por parte del clero, manifestó que nunca más, y que dichos crímenes de los últimos años nunca podían volverse a repetir. La Santa Sede envío unas directrices muy fuertes y duras para la actuación de los superiores, para los casos de pederastia entre los miembros del clero y cómo actuar en dichos casos, incluida la entrega a las autoridades civiles. El tema ha desprestigiado a la Iglesia en todo el mundo, y no es posible que paguen justos por pecadores. "A Dios lo que es de Dios y al César lo que es del César"59.

Por la tarde se inició la celebración de la canonización del beato Junípero Serra, en el Santuario nacional de la Inmaculada Concepción de Washington. Este era uno de los motivos apostólicos del viaje. Este fraile

58 Cf. MANUel ERICE, "El papa es un ejemplo para todos", en $A B C$ (24-09-2015) 51; Timothy Michael Dolan, "Un hilo común”, en La Razón (24-09-2015) 46; Yolanda Monge - JoAn Faus, "Éxtasis efímero, alegría eterna", en El País (24-09-2015) 6.

59 Cf. ABC, "Los crímenes de abuso sexual nunca deben repetirse", en ABC (24-092015) 52; Pablo Ordaz, "Crímenes de los momentos oscuros", en El País (24-09-2015) 6; Darío Menor, "Nunca más los momentos oscuros de los abusos sexuales", en La Razón (24-09-2015) 45. 
franciscano y mallorquín llamado Miguel José cambió de nombre en la profesión religiosa por el de Junípero ${ }^{60}$. Este gesto de la canonización simbolizaba el aprecio que el papa daba a la evangelización de California con un religioso español y gran impulsor de las misiones. Se trata del único español que posee una estatua en el Salón de las Estatuas del Capitolio. Aunque había movimientos en su contra, denunciando las atrocidades cometidas en tiempos de la conquista y evangelización de América, tales iniciativas fueron rechazadas de plano por parte del propio pueblo norteamericano. Nació el 24 de noviembre de 1713 y murió el 28 de agosto de 1784. Las mayores dificultades que encontraría Junípero Serra en el desarrollo de su tarea misionera, y las que más le hicieron sufrir, fueron las incomprensiones y la falta de ayuda por parte de las autoridades de California. La acción de los misioneros estaba supeditada al poder civil y militar, por lo que más de una vez los frailes se vieron oprimidos o limitados por los intereses y caprichos de quienes tenían otros ideales. El 25 de septiembre de 1988, Juan Pablo II, que había visitado la tumba de Fray Junípero en la Misión de san Carlos, lo beatificó solemnemente en Roma ${ }^{61}$.

Un día muy cargado de emociones e intenso por los temas abordados con el presidente de los Estados Unidos, que demostraba la talla de estadista del papa, el mayor compromiso por el medio ambiente y la defensa de la ecología. La reunión en el Despacho Oval había marcado pautas de comportamiento para ambas partes y la plena sintonía en dichos asuntos, llevó a la propia Casa Blanca a emitir un comunicado titulado Avanzar en los valores comunes para hacer un mundo mejor, donde denunciaba la persecución de los cristianos en Irak y Siria, la apertura de relaciones con Cuba y el desarrollo sostenible. Eran pruebas evidentes de la influencia de Francisco en Barack Obama ${ }^{62}$.

El hecho de enfrentarse a los problemas de los abusos sexuales, con sencillez, simpatía y cercanía a los prelados norteamericanos supuso un bálsamo reconfortante para toda la comunidad cristiana, escandalizada 2015) 19.

60 Cf. Sonia Valenzuela, “iSiempre adelante!”, en Vida Nueva 2958 (03-09-10-

61 Cf. Manuel Trillo, "La canonización de Junípero Serra reconoce la labor de los misioneros españoles en EE. UU.", en ABC (24-09-2015) 52; DARío MENOR, "El primer santo para los latinos estadounidenses", en La Razón (24-09-2015) 45, PABLO PARDO, "Un santo español en California”, en El Mundo (24-09-2015) 26; PAblo XimÉnez DE SANDoVAL, "Un santo para los latinos", en El País (24-09-2015) 7.

62 PABlo PARDo, "El papa reedita el efecto Obama en Washington", en El Mundo (24-09-2015) 26. 
por los innumerables hechos aberrantes. No todos confiaban en un discurso amable y apaciguador por parte del santo Padre. Pero Francisco se ganó de primera mano a todos en la catedral de san Mateo en Washington. Por ello, no dejó de ser duro con los pederastas y sus encubridores. Nunca más a los inmensos casos de escándalos, graves, desgarradores y lamentables que habían ocurrido en la Iglesia en Estados Unidos de América. La postura de Francisco fue siempre tajante respecto a los abusadores pero se mostró cercano, cariñoso y dispuesto a restañar los daños de las víctimas de tales crímenes horrendos. Se decantó por la necesidad de una autocrítica que hiciese posible, restañar todos los daños de los damnificados, y asumir las propias culpas y responsabilidades. Es necesario afrontar las humillaciones y sacrificios que comportan volver a tener la confianza en la comunidad cristiana, acercarse a curar las heridas recibidas por las víctimas. Habrá que seguir trabajando para que esos crímenes no se vuelvan a repetir jamás. Quizá este era uno de los temas más conflictivos que el papa tenía que sortear en su visita apostólica a la noble nación americana. Pero el Santo Padre no defraudó como de costumbre. Su visión de la realidad americana, la fuerza y la personalidad que evidencia, manifestó de nuevo, su gran sabiduría, su magnanimidad.

El portavoz vaticano, el P. Federico Lombardi comunicó que el Santo Padre Francisco había visitado a las Hermanitas de los Pobres, fuera del programa oficial para apoyarlas en su labor pastoral y su celo apostólico por los más necesitados ${ }^{63}$. Fue un espaldarazo para las religiosas comprometidas con los más pobres y descartados de la sociedad americana. El día 24 comenzaba con la visita al Congreso de los Estados Unidos de América. La visión desde la tribuna, para dirigirse a los congresistas y senadores era del todo imponente ${ }^{64}$. El papa pronunció el discurso en un inglés con nota, aunque reconoció que no era su fuerte. Defendió que la vida es sagrada para todos y que, por tanto, era preciso salvar por encima de todo, levantar la pena de muerte en un país que aparece como el estandarte mundial de la tolerancia, el respeto y la libertad de la persona ${ }^{65}$. También de los presos condenados a muerte. Se trata de un castigo irreversible, que en numerosas ocasiones se lleva por delante, la vida de inocentes, como prueba el hecho, de sólo desde el año 2000,

${ }^{63}$ Cf. Mercedes Gallego, "Una visita fuera de programa”, en El Diario Montañés (25-05-2015) 35 .

${ }^{64}$ Cf. Giovanni María Vian, “cerca de la gente”, en Vida Nueva 2958 (03-09-102015) 15.

65 Cf. Giovanni Maria Vian, "Proteger y defender la vida humana", en La Razón (25-09-2015) 8-9. 
las pruebas de $\mathrm{ADN}$, hayan perdonado a 263 personas que habían sido condenadas previamente, a la pena capital por asesinato. Igualmente el Santo Padre condenó el tráfico y venta de armas y animó a llevar adelante una cultura del diálogo, la colaboración y la redistribución mejor de la riqueza, pero teniendo en cuenta y poniendo de relieve el patriotismo norteamericano. La presencia del papa en el Capitolio, aunque había incomodado mucho a algunos incluso entre los católicos ${ }^{66}$, en un principio, las dudas y diferencias se disiparon pronto por la actitud de Francisco, con su espíritu de tolerancia, su defensa de la santidad de vida, la presentación de la justicia social y los derechos de las personas e invitó a tratar a los demás con la misma pasión y compasión con la que queremos todos ser tratados ${ }^{67}$. Resultó una brillante y trepidante intervención ${ }^{68}$. Al final de la mañana visitó, el Centro caritativo de la parroquia de san Patricio y encuentro con los sin techo. Posteriormente se dirigió a la base aérea de Andrews, en Washington para volar hacia Nueva York, aterrizando en el aeropuerto JFK. El Santo Padre tras un pequeño descanso se dirigió a la catedral de san Patricio para rezar las Vísperas con el clero, los religiosos y religiosas. El papa destacó lo siguiente:

"Con el propósito de ayudarles a seguir en el camino de la fidelidad a Jesucristo, me permito hacer dos breves reflexiones. La primera se refiere al espíritu de gratitud. La alegría de los hombres y mujeres que aman a Dios atrae a otros; los sacerdotes y los consagrados están llamados a descubrir y manifestar un gozo permanente por su vocación. La alegría brota de un corazón agradecido. Verdaderamente, hemos recibido mucho, tantas gracias, tantas bendiciones, y nos alegramos. Nos hará bien volver sobre nuestra vida con la gracia de la memoria. Memoria de aquel primer llamado, memoria del camino recorrido, memoria de tantas gracias recibidas... y sobre todo memoria del encuentro con Jesucristo en tantos momentos a lo largo del camino. Memoria del asombro

66 Cf. Manuel Erice, "La arenga de Francisco a una clase política en crisis", en $A B C$ (25-09-2015) 51; Mario Dorsonville, "Lo que Francisco predica ,lo vive", en $E l$ Mundo (25-09-2015) 24-25; MARC BASSETS, "El hemiciclo de las sotanas", en El País (2509-2015) 4.

67 Cf. Mercedes Gallego, "El papa pide a EE. UU. que acabe con la pena capital”, en El Diario Montañés (25-09-2015) 34-35; Mercedes GAllego, "Audiencia selecta y numerosa para la intervención hoy en la ONU”, en El Diario Montañés (25-09-2015) 35.

68 Cf. JuAn ViCEnTE Boo, "El papa critica desde el Congreso de Estados Unidos la venta de armas", en $A B C$ (25-09-2015) 50-51; DARío MENOR, "El papa reclama la abolición mundial de la pena de muerte", en La Razón (25-09-2015) 42-43; PABLO PARDO, "El papa condena la pena de muerte", en El Mundo (25-09-2015) 24; PABLo ORDAZ - MARC BASSETS, "El papa reta a la derecha de EE. UU. con un mensaje progresista en el Congreso", en El País (25-09-2015)4. 
que produce en nuestro corazón el encuentro con Jesucristo. Hermanas y hermanos, consagrados y sacerdotes, pedir la gracia de la memoria para hacer crecer el espíritu de gratitud. Preguntémonos: ¿Somos capaces de enumerar las bendiciones recibidas, o me las he olvidado? Un segundo aspecto es el espíritu de laboriosidad. Un corazón agradecido busca espontáneamente servir al Señor y llevar un estilo de vida de trabajo intenso. El recuerdo de lo mucho que Dios nos ha dado nos ayuda a entender que la renuncia a nosotros mismos para trabajar por Él y por los demás es el camino privilegiado para responder a su gran amor. [...] Gratitud y laboriosidad: estos son los dos pilares de la vida espiritual que deseaba compartir con ustedes, sacerdotes, religiosas y religiosos, esta tarde. Les doy las gracias por sus oraciones y su trabajo, así como por los sacrificios cotidianos que realizan en los diversos campos de apostolado. Muchos de ellos sólo los conoce Dios, pero dan mucho fruto a la vida de la Iglesia"69.

El viernes 25, comenzaba la jornada con la visita a la sede de la Organización de las Naciones Unidas. Previamente se reunió con el personal de la Organización, con los funcionarios y empleados para agradecerles su trabajo silencioso y escondido, pero esencial para el desarrollo de toda la labor de la ONU70. A ellos, fueron dedicadas sus primeras palabras, de manera expresa como eran los traductores, secretarias, personal de limpieza, cocineros, personal de seguridad y mantenimiento. Algo inaudito y nunca visto anteriormente. A continuación el papa entró al recinto de la Asamblea General para el encuentro con sus miembros. Entre otras cosas destacó:

"No bastan, sin embargo, los compromisos asumidos solemnemente, aunque constituyen ciertamente un paso necesario para las soluciones. La definición clásica de justicia a que aludi anteriormente contiene como elemento esencial una voluntad constante y perpetua: Iustitia est constans et perpetua voluntas ius suum cuique tribuendi. El mundo reclama de todos los gobernantes una voluntad efectiva, práctica, constante, de pasos concretos y medidas inmediatas, para preservar y mejorar el ambiente natural y vencer cuanto antes el fenómeno de la exclusión social y económica, con sus tristes consecuencias de trata de seres humanos, comercio de órganos y tejidos humanos, explotación sexual de niños y niñas, trabajo esclavo, incluyendo la prostitución, tráfico de drogas y de armas, terrorismo y crimen internacional organizado. Es tal

69 Cf. Se puede en http://w2.vatican.va/content/francesco/es/homilies/2015/documents/papa-francesco_20150924_usa-omelia-vespri-nyc.html Visto 13-10-2015.

70 Cf. Carlos Soler, "La palabra libre de la Santa Sede en la ONU", en Vida Nueva 2958 (03-09-10-2015) 14. 
la magnitud de estas situaciones y el grado de vidas inocentes que va cobrando, que hemos de evitar toda tentación de caer en un nominalismo declaracionista con efecto tranquilizador en las conciencias. Debemos cuidar que nuestras instituciones sean realmente efectivas en la lucha contra todos estos flagelos. [...] Comencé esta intervención recordando las visitas de mis predecesores. Quisiera ahora que mis palabras fueran especialmente como una continuación de las palabras finales del discurso de Pablo VI, pronunciado hace casi exactamente 50 años, pero de valor perenne, cito: "Ha llegado la hora en que se impone una pausa, un momento de recogimiento, de reflexión, casi de oración: volver a pensar en nuestro común origen, en nuestra historia, en nuestro destino común. Nunca, como hoy, [...] ha sido tan necesaria la conciencia moral del hombre, porque el peligro no viene ni del progreso ni de la ciencia, que, bien utilizados, podrán [...] resolver muchos de los graves problemas que afligen a la humanidad» (Discurso a los Representantes de los Estados, 4 de octubre de 1965). Entre otras cosas, sin duda, la genialidad humana, bien aplicada, ayudará a resolver los graves desafíos de la degradación ecológica y de la exclusión. Continúo con Pablo VI: «El verdadero peligro está en el hombre, que dispone de instrumentos cada vez más poderosos, capaces de llevar tanto a la ruina como a las más altas conquistas» (ibíd.). Hasta aquí Pablo VI. [...]

El discurso sigue más adelante:

"La casa común de todos los hombres debe continuar levantándose sobre una recta comprensión de la fraternidad universal y sobre el respeto de la sacralidad de cada vida humana, de cada hombre y cada mujer; de los pobres, de los ancianos, de los niños, de los enfermos, de los no nacidos, de los desocupados, de los abandonados, de los que se juzgan descartables porque no se los considera más que números de una u otra estadística. La casa común de todos los hombres debe también edificarse sobre la comprensión de una cierta sacralidad de la naturaleza creada"71.

Fue el cuarto papa que habló claro ante los miembros de la Asamblea General de Naciones Unidas ${ }^{72}$. Pablo VI73, Juan Pablo II en dos ocasiones, Benedicto XVI y Francisco. Criticó a las instituciones financieras internacionales por ahogar en muchas ocasiones el desarrollo de las más

71 Cf. http://w2.vatican.va/content/francesco/es/speeches/2015/september/documents/papa-francesco_20150925_onu-visita.html Visto 13-10-2015.

72 Cf. BAN KI-MoON, "Valores compartidos para un futuro común", en La Razón (25-09-2015) 42-43.

73 Cf. Javier Ansorena, “Tras las huellas de Pablo VI”, en $A B C$ (25-09-2015) 52. 
necesitadas ${ }^{74}$. Siempre con guante de seda, como aplicó el discurso en el Capitolio a senadores y congresistas ${ }^{75}$, exactamente igual cuando ahondó en expresiones en Cuba. El viaje se estaba desarrollando con unos discursos y homilías donde se ponía hincapié en dar las paletadas con cal y arena $^{76}$. También lanzó diatribas contra la pobreza y frenar la desigualdad social y conseguir un desarrollo sostenible ${ }^{77}$. A continuación mantuvo un encuentro interreligioso en el Memorial de la Zona Cero. Realidad llena de emoción que el papa también vivió en primera persona. Lugar que quiere ser memorial de las personas que allí murieron, y que el Santo Padre recordó y se acercó a los familiares de aquella tragedia ${ }^{78}$. Reconoció la labor más entregada de la policía y los bomberos de Nueva York que dieron hasta su vida por salvar a sus compatriotas como un acto de caridad suprema ${ }^{79}$.

Por la tarde se fue a visitar la Escuela Nuestra Señora de los Ángeles para encontrarse con niños y familias de emigrantes, en Nueva York, en el barrio de Harlem ${ }^{80}$. Aquí el papa besó y abrazó a todos los que se lo pedían. Mucho más sonriente y relajado fue saludando a todos y cada uno y poniendo los deberes a los jóvenes. El recibimiento fue por igual por parte de maestros, niños y padres. Fue elegido personalmente por el papa con los grandes porcentajes de estudiantes hispanos en un $70 \%$ y de afroamericanos en un 30\% aproximadamente. Fue el lugar idóneo para estar con los niños ${ }^{81}$. La jornada del viernes acabaría con la celebración de la Eucaristía en el Madison Square Garden, ante más de 15.000 asis-

74 Cf. Mercedes Gallego, "El papa lleva a la ONU la voz del pueblo", en El Diario Montañés (26-09-2015) 42-43.

75 Cf. José Luis Peñalva, "Han visto a Cristo”, en El Diario Montañés (26-09-2015) 43.

76 Cf. JUAN VICENTE Boo, "El papa condena en la ONU el irresponsable desgobierno de la economía mundial", en $A B C$ (26-09-2015) 44-45; DARío Menor, "El papa, a los líderes mundiales: Acciones y no palabras", en La Razón (26-09-2015) 36-37; PABLo Pardo - Carolina Martín, "El papa, estrella en Nueva York", en El Mundo (26-092015) 1 y 24-25; PABLO ORDAZ, "El papa apoya a Obama en el pacto nuclear con Irán”, en El País (26-09-2015) 5.

77 Cf. AlEJANDRo CARRA, "La nueva agenda del planeta para combatir la pobreza", en $A B C$ (26-09-2015) 45.

78 Cf. Mercedes Gallego, "Bajo el peso de las Torres Gemelas", en El Diario Montañés (26-09-2015) 43.

79 Cf. Darío Menor, "Donde el dolor grita al cielo", en La Razón (26-09-2015) 37; Pablo Pardo - Carolina Martín, "El papa, estrella en Nueva York", en El Mundo (2609-2015) 24.

80 Cf. Pablo Ordaz, “Todos mis sueños dependen de unos papeles”, en El País (2709-2015) 4.

81 Cf. Pablo Pardo - Carolina Martín, "El papa, estrella en Nueva York", en El Mundo (26-09-2015) 25. 
tentes que le recibieron entre grandes aplausos y puestos en pie. El papa se refirió especialmente a la evangelización de las grandes ciudades tan necesitadas de humanidad, advirtiendo que Jesús sigue caminando entre todos nosotros, incluso en las inmensas metrópolis de hoy en día. Puso mucho tesón en los emigrantes, para los extranjeros y a sus hijos que en muchas ocasiones no logran la escolarización, necesaria para su desarrollo personal e intelectual. Algo tan evidente que salta a los ojos de todos como fue el acercarse a un padre con hija pequeñita a hombros, que llevaba una sonda. Francisco se aproximó y la dio un beso. Gestos que calan en cualquier persona de buen corazón. Muchos gestos, sin duda, acompañados de las palabras claves ${ }^{82}$. El sábado 26, el Santo Padre viajó de Nueva York, desde el JFK, hasta el aeropuerto internacional de Filadelfia. Hacia las 10,30 comenzaba la celebración de la Misa con los obispos, sacerdotes, religiosos y religiosas de Pensilvania, en la catedral de san Pedro y san Pablo de Filadelfia. Sin duda lo más destacado fue la afirmación de la mujer y su papel en la Iglesia y la comunidad cristiana. La Iglesia nunca podrá pagar la inmensa contribución que todas ellas hacen a la Iglesia. Pero al mismo tiempo el Santo Padre pedía que la misma Iglesia valorase con todas sus energías a la mujer ${ }^{83}$. A primera hora de la tarde se fue a un acto sobre la libertad religiosa y al mismo tiempo reunirse con la Comunidad Hispana y otros inmigrantes, en el Independence Mall de Filadelfia ${ }^{84}$. El papa les pidió que ni renuncien ni se avergüencen de sus raíces ${ }^{85}$. Esta reunión sirvió para encontrarse con refugiados y $\sin$ papeles de todo el mundo. Toda emigración lleva consigo un coste emocional, familiar y personal. Por tanto, es necesario tener a mano una buena dosis de esperanza en una nueva vida. Siempre esperanza. Todos aportan sus tradiciones, cultura y tradiciones que han de conservarse

82 Cf. JuAn Vicente Boo, "Francisco clama contra el anonimato ensordecedor de los ciudadanos de segunda", en ABC (26-09-2015) 46; Mercedes Gallego, "Música y oración inundaron el Madison Square Garden", en El Diario Montañés (27-09-2015) 49; Pablo PARdo - Carolina Martín, "El papa, estrella en Nueva York", en El Mundo (2609-2015) 25; José Luis Peñalva, "Repartir 100.000 hostias, en El Diario Montañés (27-092015) 49.

83 Cf. JUAN ViCENTE Boo, "El papa invita a valorar la inmensa contribución de las mujeres a la Iglesia", en $A B C$ (27-09-2015) 64-65; DARío MENor, "El papa pide que la Iglesia valore más a la mujer", en La Razón (27-09-2015) 42-43.

84 Cf. Pablo Pardo, "Los desposeídos del papa", en El Mundo (27-09-2015) 26-27; Mercedes Gallego, "Los milagros de un papa moderno", en El Diario Montañés (27-092015) 48-49; PABLo ORDAZ, "El papa pide a los hispanos de EE. UU. que no se avergüencen de sus raíces", en El País (27-09-2015) 4.

85 Cf. Darío Menor, "Bergoglio insufla orgullo a los hispanos", en Vida Nueva 2958 (03-09-10-2015) 16-18. 
como un preciado tesoro ${ }^{86}$. En esto han de empeñarse todos, con su espíritu de sacrificio y abnegación que llevan consigo. También se refirió a las familias, puesto que se estaba celebrando el VIII Encuentro Mundial87. Ya a última hora de la tarde se celebró la Fiesta de las Familias y una Vigilia de Oración en el Benjamín Franklin Parkway de Filadelfia.

El papa improvisó su discurso del que podemos decir:

"Y no quiero seguir hablando porque se hace demasiado largo, pero quisiera marcar dos puntitos de la familia en los que quisiera que se tuviera un especial cuidado. No sólo quisiera, tenemos que tener un especial cuidado. Los niños y los abuelos. Los niños y los jóvenes son el futuro, son la fuerza, los que llevan adelante. Son aquellos en los que ponemos esperanza. Los abuelos son la memoria de la familia. Son los que nos dieron la fe, nos transmitieron la fe. Cuidar a los abuelos y cuidar a los niños es la muestra de amor -no sé si más grande, pero yo diría-más promisoria de la familia, porque promete el futuro. Un pueblo que no sabe cuidar a los niños y un pueblo que no sabe cuidar a los abuelos, es un pueblo sin futuro, porque no tiene la fuerza y no tiene la memoria que lo lleve adelante. La familia es bella, pero cuesta, trae problemas. En la familia a veces hay enemistades. El marido se pelea con la mujer, o se miran mal, o los hijos con el padre. Les sugiero un consejo: Nunca terminen el día sin hacer la paz en la familia. En una familia no se puede terminar el día en guerra. Que Dios los bendiga. Que Dios les dé fuerzas. Que Dios los anime a seguir adelante. Cuidemos la familia. Defendamos la familia porque ahí se juega nuestro futuro. Gracias. Que Dios los bendiga y recen por mí, por favor"88.

El domingo 27, el papa se dirigió al encuentro con los obispos invitados al Encuentro Mundial de las Familias, en el Seminario Mayor san Carlos Borromeo. De manera previa, estuvo con un grupo de víctimas de abusos sexuales ${ }^{89}$. Quizá sus palabras resonaron muy fuertes en sus oídos:

86 Cf. Pablo Pardo, "Francisco reclama a los laicos participación", en El Mundo (27-09-2015) 27.

87 Cf. Cf. Ginés García Beltrán, "La belleza de la Familia”, en La Razón (27-092015) 43; DARío Menor, "El desafío urgente de los gobiernos en la defensa de la familia", en La Razón (28-09-2015) 57.

88 Cf. http://w2.vatican.va/content/francesco/es/speeches/2015/september/documents/papa-francesco_20150926_usa-festa-famiglie.html Visto 13-10-2015.

89 Cf. Mercedes Gallego, "El Vaticano rebaja la promesa papal a las víctimas de abusos sexuales", en El Diario Montañés (28-09-2015) 39; JuAn Vicente Boo, "El papa afirma que el clero rendirá cuentas si abusa o no protege a los niños", en $A B C$ (28-09-2015) 60-61; DARío Menor, "El papa, sobre los abusos: Todos rendirán cuentas”, en La Razón 
"Para aquellos que fueron abusados por un miembro del clero, lamento profundamente las veces en que ustedes o sus familias denunciaron abusos pero no fueron escuchados o creídos. Sepan que el Santo Padre les escucha y les cree. Lamento profundamente que algunos obispos no cumplieran con su responsabilidad de proteger a los menores. Es muy inquietante saber que en algunos casos incluso los obispos eran ellos mismos los abusadores. Me comprometo a seguir el camino de la verdad, dondequiera que nos pueda llevar. El clero y los obispos tendrán que rendir cuentas de sus acciones cuando abusen o no protejan a los menores" 90 .

Más tarde se dirigió a visitar a los presos del Instituto Correccional Curran- Fromhold. Llegó, vio y venció igualmente con los reclusos. El papa reivindicó la reinserción social de los presos, en el país que posee mayor población carcelaria de todo el mundo. Francisco quiso llevar la luz hasta el mismo corazón de la mayor prisión del Estado de Pensilvania, en una sala cerrada donde se había dispuesto a unos cien presos y a algunos de sus familiares. Ante las palabras del Santo Padre, hubo muchos que se les quebró el interior, refiriéndose a sus familias y cuando ponía todo su labor paternal para la escucha de sus situaciones, cada una tan particular. Se encontró con violadores, ladrones y asesinos, muchos de ellos en espera de juicio ${ }^{91}$.

Por la tarde le esperaba el plato fuerte de la celebración Eucarística para la Clausura del VIII Encuentro Mundial de las Familias, en el Benjamín Franklin Parkway de Filadelfia. El papa al dirigirse a las familias, dijo:

“La fe abre la «ventana» a la presencia actuante del Espíritu y nos muestra que, como la felicidad, la santidad está siempre ligada a los pequeños gestos. "El que les dé a beber un vaso de agua en mi nombre -dice Jesús, pequeño gesto- no se quedará sin recompensa» (Mc 9,41). Son gestos mínimos que uno aprende en el hogar; gestos de familia que se pierden en el anonimato de la cotidianidad pero que hacen diferente cada jornada. Son gestos de madre, de abuela, de padre, de abuelo, de hijo, de hermanos. Son gestos de ternura, de cariño, de compasión. Son gestos del plato caliente de quien espera a cenar, del desayuno temprano

(28-09-2015) 56; Pablo Ordaz, "El papa promete justicia a las víctimas de abusos", en El País (28-09-2015) 6.

90 Cf. http://w2.vatican.va/content/francesco/es/speeches/2015/september/documents/papa-francesco_20150927_usa-vittime-abusi.html Visto 13-10-2015.

91 Cf. Mercedes Gallego, "El papa conquista también los reclusos", en El Diario Montañés (28-09-2015) 38; JUAN VICENTE Boo, "Francisco saluda uno por uno a un centenar de presos en la cárcel de Filadelfia", en $A B C$ (28-09-2015) 61; PABLO PARdo, "El papa, en la cárcel del dolor”, en El Mundo (28-09-2015) 24. 
del que sabe acompañar a madrugar. Son gestos de hogar. Es la bendición antes de dormir y el abrazo al regresar de una larga jornada de trabajo. El amor se manifiesta en pequeñas cosas, en la atención mínima a lo cotidiano que hace que la vida siempre tenga sabor a hogar. La fe crece con la práctica y es plasmada por el amor. Por eso, nuestras familias, nuestros hogares, son verdaderas Iglesias domésticas. Es el lugar propio donde la fe se hace vida y la vida crece en la fe"92.

El punto final se hizo con el saludo al Comité organizador, los voluntarios y benefactores, en el recinto del aeropuerto internacional de Filadelfia. Tras la ceremonia de despedida, a cargo del vicepresidente Joe Biden, el avión de American Airlines, con Francisco a bordo, ponía rumbo a Roma.

Era el final de un viaje apostólico que fue el más largo de los realizados por Francisco. Durante el vuelo de regreso, el papa volvió a dar la rueda de prensa ya tradicional en sus viajes. Entre las preguntas se encuentra la del periodista David O'Reilly, de Philadelphia Inquirer.

Santo Padre, Filadelfia -como usted sabe- ha pasado un mal período con los abusos sexuales: todavía es una herida abierta en Filadelfia. Sé que muchos en Filadelfia se han sorprendido porque en su alocución a los obispos en Washington les ha ofrecido consolación y conforto. Creo que muchos en Filadelfia querrían preguntarle: “¿Por qué ha sentido la necesidad de ofrecer consolación y conforto a los obispos?"

"En Washington he hablado a todos los obispos de los Estados Unidos: Estaban todos, ¿no?, de todo el País. He sentido la necesidad de expresar compasión porque ha ocurrido algo muy feo, y muchos de ellos han sufrido tanto porque no lo sabían, o porque cuando explotó el asunto han sufrido mucho: hombres de Iglesia, de oración, auténticos pastores... Y yo he dicho que sabía que ellos -y he usado una palabra de la Biblia, del Apocalipsis- "ustedes vienen de la gran tribulación”: esto es lo que ha sucedido y ha sido una gran tribulación. Pero no sólo el sufrimiento afectivo: es lo que hoy he dicho al grupo de personas que han sufrido abusos. Ha sido... no digo "apostasía”, pero sí casi un sacrilegio. Sabemos que los abusos se dan por doquier: en el ámbito familiar, en el ámbito vecinal, en las escuelas, en los gimnasios, en todas partes. Pero cuando un sacerdote comete un abuso, es gravísimo, porque la vocación del sacerdote es hacer que ese niño, esa muchacha crezca hacia lo alto, hacia el amor de Dios, hacia la madurez afectiva, hacia el

92 Cf. Se puede en http://w2.vatican.va/content/francesco/es/homilies/2015/documents/papa-francesco_20150927_usa-omelia-famiglie.html Visto 13-10-2015. 
bien... Y en lugar de hacer esto el mal lo ha destrozado, la ha machacado. Y por esto es casi un sacrilegio. Y él ha traicionado la vocación, la llamada del Señor. Por eso, en este momento, la Iglesia es fuerte en esto; tampoco se debe encubrir: también son culpables los que han encubierto estas cosas. También algunos obispos que han encubierto esto. Es algo muy feo. Y las palabras de conforto no quieren decir: "Esté tranquilo, no es nada; no, no. Las cosas han sido así, pero "han sido tan feas, y yo me imagino que ustedes han llorado mucho": ese es el sentido de las palabras. Y hoy he hablado duramente"93.

El Santo Padre Francisco quitó triunfalismo sobre su posible éxito arrollador del viaje a Cuba y Estados Unidos de América. Fue recibido como una estrella pero el papa giró en seguida la conversación al mostrar el lado más personal, incluso sus debilidades, me siento débil y tengo miedo de mí mismo y que en ningún momento se había sentido como tal estrella. Fue en todo momento un encuentro que se desarrolló en un tono cordial, amable y distendido y que valoró positivamente la labor realizada por los religiosos y religiosas en la educación y ayuda social al conjunto de la sociedad americana ${ }^{94}$. Pero sí existía un clamor general entre los periodistas que acompañaban a Francisco en el regreso a Roma, era la coincidencia en el éxito del viaje apostólico en su conjunto. Finalmente, el avión que conducía al Santo Padre aterrizaba en el aeropuerto romano de Ciampino, a las 09,50 de la mañana, hora local de Roma. Así concluía el décimo viaje que había llevado al papa a Cuba y a Estados Unidos y que habría sellado el reinicio de las relaciones diplomáticas entre ambos países ${ }^{95}$. La supresión del embargo, ¿para cuándo?

\section{Balance}

Durante su visita a Cuba96, el papa Francisco llevó a cabo una intensa agenda en las ciudades de La Habana, Holguín y Santiago, donde ofi-

93 Cf. http://w2.vatican.va/content/francesco/es/speeches/2015/september/documents/papa-francesco_20150927_usa-conferenza-stampa.html Visto 13-10-2015.

94 Cf. Juan Vicente Boo, "El papa: Tengo miedo de mí mismo", en ABC (29.09$2015)$ 48; FRAN OTERO, "Los muros para frenar la migración siempre caen", en La Razón (29-09-2015) 46; ColPISA / AfP. Roma, "Tengo miedo de mí mismo porque me siento débil", en El Diario Montañés (29-09-2015) 58.

95 Cf. Jesús de las Heras Muela, "Viaje pastoral y mucho más”, en Ecclesia 3797 (19-09-2015) 16-17.

96 Cf. Editorial, "El viaje del papa Francisco a Cuba y el servicio y misión de la Iglesia", en Ecclesia 3798 (26-09-2015) 5. 
ció dos misas multitudinarias al aire libre, más otra dentro del Santuario de la Virgen de la Caridad, y mantuvo encuentros con jóvenes, familias y con religiosos católicos de la Isla caribeña. Las críticas al régimen fueron muy veladas y tampoco hubo ningún tipo de reunión con la disidencia.

Se reunió con el presidente Raúl Castro, quien acompañado de los miembros de su Gobierno, asistió a las misas que el Santo Padre celebró en las tres ciudades escenario de su visita. "Si el papa sigue hablando así, tarde o temprano empezaré a rezar otra vez y volveré a la Iglesia católica, y no es broma", había asegurado Castro después de que Francisco lo recibiera en una audiencia en el Vaticano. Cumplió con la promesa de asistir a las celebraciones eucarísticas que el papa oficiara en Cuba. "Puede que empiece a creer e incluso puede que asista alguna misa en La Habana". El Santo Padre Francisco también vio en La Habana al ex presidente cubano Fidel Castro, de 89 años y retirado del poder desde 2006, con quien mantuvo un encuentro distendido y familiar. Con Fidel Castro habló durante unos 40 minutos e intercambiaron libros como regalo. El ex mandatario recibió a Francisco con la ropa deportiva con la que se le suele ver desde hace años. El papa de 78 años expresó su "especial consideración y respeto" por Fidel Castro apenas llegó a la Isla.

El papa Francisco llegó a la Isla cubana como un símbolo del acercamiento entre Cuba y Estados Unidos. El papa de origen argentino, medió de forma directa entre los jefes de Estado de ambos países, viejos enemigos ideológicos que durante los 18 meses hubo una serie de contactos secretos antes del anuncio del deshielo en diciembre de 2014. Francisco habló en la Isla de esperanza por la nueva era entre Washington y La Habana, y Raúl Castro le volvió a agradecer su apoyo al diálogo bilateral. Este era uno de los aspectos más importantes para todas las partes.

El Santo Padre Francisco no se llegó a reunir con los disidentes al régimen, como pedían muchos activistas y varias organizaciones internacionales. Dos conocidas opositoras fueron detenidas para evitar que asistieran a las recepciones en las que debía acudir el papa Francisco. Grupos opositores denunciaron al menos 50 arrestos en el marco de la visita papal, sobre todo para impedir a los activistas asistir a la multitudinaria misa que Francisco ofició en la Plaza de la Revolución de La Habana el domingo. Luego trascendió que habían sido más de 200, los detenidos. Por último en Santiago de Cuba, durante su homilía en el Santuario de la Virgen de la Caridad del Cobre, Francisco instó a sembrar reconciliación y dijo que la Iglesia quiere tender puentes y romper muros. En sus mensajes pastorales, desde el principio en La Habana, rechazó sin embargo el 
exceso de ideología y abogó a menudo por la reconciliación, dirigiéndose a todos los cubanos. No se sirve a las ideas, sino que se sirve a las personas, dijo el papa durante una multitudinaria misa en La Habana. Por eso lo primero que ha hecho Francisco nada más llegar a la capital cubana, ha sido pedir más espacios, libertad y medios, para la Iglesia en Cuba ${ }^{97}$. Evidentemente el papa ha apostado muy fuerte por los intereses de la Iglesia cubana y por la acción de la Santa Sede.

Hasta la llegada del papa a Norteamérica ${ }^{98}$, los medios de comunicación han acentuado el tema de la protección del Santo Padre. Nunca, en la historia de Estados Unidos, ha habido un operativo tan grande de seguridad, como el que ha provocado la llegada del papa Francisco. Comentaba un miembro del Servicio Secreto, que desde fines de agosto ningún miembro de dicha agencia tuvo autorización para tomarse vacaciones, ante la necesidad de contar con todos los recursos para preservar la seguridad del Santo Padre.

Hay clara conciencia que su viaje es pastoral, y que desea fortalecer la fe de los creyentes y evangelizar, pero no deja de mencionar con énfasis que su meta es también tender lazos de unidad entre las personas y países en el mundo, y llamar la atención sobre temas esenciales, como la protección del medio ambiente, la inmigración y la dignidad del inmigrante, el hambre en el mundo, la importancia de la familia como núcleo de la sociedad, etc.

Dado que la Iglesia estadounidense ha acentuado en los últimos años con marcada unilateralidad la importancia de combatir el aborto, la anticoncepción y el llamado "matrimonio igualitario", los medios de comunicación, que tienden a ser liberales, han mencionado estos temas, sin duda, controvertidos para la sociedad, cada vez que mencionaban a la Iglesia o al papa. Y su perspectiva, claro, era más bien de crítica. A los temas mencionados, se sumaba siempre, y sin falta, el que muchos menores sufrieran abusos sexuales de manos de presbíteros. Un papa afectivo, humilde, sencillo, parece haberse ganado el corazón de la gente de medios en Estados Unidos. Hablando de política, expresan que no es ni republicano ni demócrata. En el campo de la economía, explican que critica al capitalismo, pero también al comunismo. Buscan el equilibrio. Y hasta, increíble, defenderlo.

97 Cf. Se puede ver en http://www.laprensagrafica.com/2015/09/22/seis-cosas-quedejo-la-visita-del-papa-francisco-a-cuba\#sthash.ydq6tm4h.dpuf Visto 12-10-2015.

98 Cf. Editorial, "El papa Francisco en Estados Unidos: profeta y testigo de fraternidad universal”, en Ecclesia 3799 (03-10-2015) 5. 
Hay al menos dos razones poderosas que motivan a los liberales (demócratas) a apoyar al papa: la protección del medio ambiente y el combate al calentamiento global (cuya relación con conductas humanas, los republicanos niegan totalmente), y la justicia social, el seguro social (a lo que los republicanos se resisten). Pero también tienen dos razones importantes para combatirlo: los demócratas suelen favorecer el aborto, y presionan irrestrictamente la agenda del lobby gay.

El papa se los ha ganado a los medios de comunicación como la CNN, Fox News y otras cadenas hablan de que Francisco es un hombre de fe, de esperanza, a quien todo el mundo quiere. Remarcan constantemente sus gestos de humildad, que no vive en el lujoso aposento del Vaticano, que utiliza vehículos sencillos, como el Fiat 500 que ayer lo llevó a la Nunciatura Apostólica en Washington, rodeado de 4x4 blindados, y expresan su admiración por la pasión de Francisco de visitar a los más necesitados, inmigrantes, presidiarios, enfermos. Y, llamativo, ¡le creen! Son conscientes de que no se trata de una fachada, sino de una actitud muy auténtica, noble y pura.

No podemos afirmar que el papa se haya ganado al pueblo estadounidense. En realidad, no creemos que esto suceda. En los próximos días habrá en Washington, Nueva York y Filadelfia excepcionales muestras de fe, pero, claro, especialmente de parte de católicos, que conforman un cuarto de la población del país. El 75 por ciento restante, se estará nutriendo especialmente de los medios liberales, que pasaron a admirar a Francisco, y que a través de este giro, comienzan a tener una imagen positiva de la Iglesia, comprometida con los necesitados, con la justicia social, con los destinos de la humanidad. La Iglesia estadounidense está aprendiendo a no encasillarse exclusivamente en sólo dos temas, sino que con Francisco, aprende a ver el mensaje del Evangelio desde una perspectiva amplia, completa, abarcando toda la realidad de la dignidad de la persona. Y de una forma eficiente. Y eso tiene consecuencias también positivas en todo el mundo, incluyendo los medios de comunicación ${ }^{99}$.

\section{Conclusión}

Francisco llegó a Cuba como el misionero de la misericordia y dispone de nuevo sus maletas para entrar en los Estados Unidos de América

99 Cf. Se puede consultar https://www.archimadrid.org/index.php/oficina-de-informacion/noticias-mundo/item/79160-francisco-conquisto-a-los-medios-de-comunicacion-enestados-unidos Visto 12-10-2015. 
como el misionero de la caridad. Un gira, que debe tender puentes y derribar los muros que todavía permanecen, que deben escenificar una de las características esenciales del ministerio petrino de Francisco, la creación de puentes de diálogo y reconciliación y derribar los muros del embargo económico y del enfrentamiento social. El papa Francisco ha finalizado la primera etapa de su viaje (Cuba), la más fácil de su periplo americano e inicia la más complicada y delicada. En la Cuba de los Castro Ruz, esperaban a un héroe y a un amigo, a un gran compatriota latinoamericano, casi padre de la patria, que les salvase de su mísera realidad. Vieron a un hombre de Dios, entregado a su misión y al servicio de los hombres; más que a un padre de la patria a un padre espiritual que anuncia la Buena Nueva.

En Norteamérica pueden ver que llega el villano, que pone en tela de juicio el capitalismo salvaje y a veces despiadado que busca los intereses económicos por encima de la persona. No toda la sociedad americana está de acuerdo con las opiniones del Santo Padre, incluso desde los sectores católicos tan conservadores, que han puesto en tela de juicio las mismas encíclicas como Laudato Si. El viaje se inicia desde el ambiente de la calidez de las gentes, acostumbradas al clima tropical, a la vivencia de una frialdad típicamente anglosajona que podría distanciar los objetivos del papa, en un clima más continental e incluso en ocasiones gélido.

Si en Cuba, dejó un pueblo mucho más esperanzado del que encontró, pues el recurso constante al diálogo, consiguió poder vislumbrar una salida para el régimen cubano, y finalmente, poder quebrar el embargo norteamericano, pues muchos de los pasos que ya podían darse se han hecho por parte del presidente Barack Obama. Encontró un pueblo, bien dispuesto, cercano y muy atento a lo que en sus discursos, encuentros y homilías, destacaba, mantenía y opinaba. También se han reconocido por ambas partes, los buenos oficios y la fructífera mediación de los problemas entre Estados Unidos y Cuba, que propiciaron el restablecimiento de las relaciones diplomáticas plenas. Algo inusitado que nadie podía haber creído hace dos años, cuando el régimen cubano se encontraba al borde del abismo, ante las dificultades que atravesaba la Venezuela bolivariana, único sostén de la rancia economía cubana. Pero sus dignatarios, estudiaron, evaluaron y decidieron, la importancia, la fuerza y el prestigio que tenía la Iglesia, y por supuesto la Santa Sede, para tratar de buscar un acercamiento paulatino y constante en sus demandas justas del levantamiento del embargo económico y comercial, por parte de EE. UU. Sin duda, el cardenal arzobispo de La Habana, Jaime Lucas Ortega y Alami- 
no, había jugado sus bazas como mediador entre el régimen y la Curia romana. Pero la impronta de Francisco pesaba y mucho.

\section{Respecto a la República de Cuba}

Podemos afirmar que el papa, siempre confío en la Virgen de la Caridad del Cobre, patrona de Cuba, para que todos sus hijos se reconciliaran, los de dentro y los de fuera y se acogiera a su manto protector.

Podemos decir que el Santo Padre, transmitió las bases de la revolución, no la de los hermanos Castro Ruz, sino la revolución de la ternura, María Madre de la Caridad y de la misericordia Dios que siempre perdona.

Podemos afirmar que el papa, vela permanentemente por los valores de la familia, valores puestos en entredicho, pero que son una nueva oportunidad para la humanidad en todo su conjunto.

Podemos anunciar que el Pontífice alude permanentemente a soñar, que los cristianos, que los hombres sigan soñando con el Señor, que siempre es fiel a sus promesas y que no se olviden de Él, más allá de las circunstancias personales.

Podemos confirmar con el Santo Padre que Dios nos mira, nos sonríe amablemente, tiernamente, con amor de padre y de madre y su rostro es el de Jesús, su Hijo. Incluso cuando nosotros torcemos la cabeza para no enfrentarnos a su amor.

Podemos creer con el Romano Pontífice, que Dios desea una Iglesia pobre, que esté y se ponga al servicio de los más necesitados, de los más próximos, de los más pobres, que son, sin duda, nuestros prójimos. Una Iglesia pobre entre los pobres.

Podemos vivir con el papa, la opción por la reconciliación mutua. Tanto a nivel personal como comunitario, donde queda reflejado el diálogo y el compromiso social que podemos ver en este caso, la reconciliación entre dos los pueblos americanos Cuba y Estados Unidos de América.

Podemos aceptar con el Santo Padre, que quien no vive para servir no sirve para vivir. La vida ha de ser un auténtico servicio para todos los demás. Un servicio desinteresado que se ofrece desde la caridad y el amor. De lo contrario no servimos para vivir.

Podemos decir con el Pontífice, que en la vida se han de trazar puentes, uno tras otro, sin descanso ni desmayo. Pues puente tras puente, ire- 
mos consiguiendo construir el gran puente del entendimiento, del consenso, de la paz.

Podemos concluir con el papa Francisco aquello de que estoy con vosotros como misionero de la misericordia, porque el objetivo de su gira pastoral, era anunciar por encima de todo la gran misericordia del Señor.

Aquí se han hecho proféticas las palabras de san Juan Pablo II, en su viaje a Cuba cuando manifestó: Que Cuba se abra con todas sus magníficas posibilidades al mundo y que el mundo se abra a Cuba ${ }^{100}$. Será esto ya posible en la Cuba del siglo XXI, tras el viaje de Francisco.

\section{Respecto a Estados Unidos de América}

Podemos decir que el papa es un pontífice verde, en alusión a los temas sobre medio ambiente y sobre la ecología y el cuidado del planeta. La repercusión de la encíclica Laudato Si, es más que evidente.

Podemos afirmar que el Santo Padre es de los sin papeles, en firme alusión a los extranjeros, refugiados, hijo de emigrantes italianos, que no deben renunciar a sus raíces. Su defensa de los desterrados y refugiados lo demuestra.

Podemos asumir que el Pontífice está en contra de la pena de muerte, es una sociedad como la norteamericana que mantiene todavía hoy la pena capital. Hoy no se puede sostener tal práctica en nuestra sociedad civilizada del siglo XXI.

Podemos aclarar que el Romano Pontífice es antinuclear, por oponerse a dichas armas, al tráfico de las mismas y desarrollar la acción política con sinceridad, constancia y firmeza. Lo ha denunciado por activa y pasiva y ha apostado por los tratados de no proliferación de las armas nucleares.

Podemos situar al papa como de la familia, atacada desde dentro y fuera de la misma institución, pero que es esencial para el futuro de la humanidad. La convocatoria del Sínodo especial sobre ella, en Roma, lo atestigua.

Podemos afirmar que el Santo Padre está en contra de todos los abusos sexuales, ejercidos por los clérigos contra los menores. Los res-

100 Cf. Se puede encontrar en http://w2.vatican.va/content/john-paul-ii/es/speeches/1998/january/documents/hf_jp-ii_spe_19980121_lahavana-arrival.html Visto 13-102015. 
ponsables deben ser castigados. Es un hecho sin precedentes que la Santa Sede haya dispuesto sus protocolos de actuación respecto a dicho tema.

Podemos mantener que el Pontífice, es el adalid de la solidaridad, centrada en las grandes ciudades que necesitan de la ayuda, el amor y el sacrificio personal. Es la palabra clave en su pontificado y en sus escritos.

Podemos decir que el Romano Pontífice, afirma siempre la dignidad de la persona, más allá de la situación concreta en la que se encuentre personalmente. Porque sin la dignidad de la persona, todo lo demás, cae por su propio peso.

Podemos afirmar que es el papa de los gestos, signos y símbolos, aparece con automóviles más sencillos y utilitarios del mercado, que van más lejos que las palabras.

Podemos plantear que es el Santo Padre de la humildad, pues siempre termina sus discursos y homilías con la frase: Por favor, recen por mí. Ésta ha sido su tónica desde el momento de su elección, verificada en todos sus encuentros y celebraciones.

Este viaje apostólico, el décimo de su pontificado fuera de Italia suponía el reto más ambicioso acometido hasta el presente por sus mismas características. El desafío de la Iglesia, ha sido siempre, la cercanía a la gente, la proximidad a sus hijos. Francisco es ante todo un Pastor de la Iglesia católica, es un líder espiritual respaldado por su integridad moral, es un cristiano convencido y un católico ejemplar. ¿Se puede pedir más? 